\title{
ENTRE PREVISIONES Y POSIBILIDADES
}

\author{
Respuestas al cuestionario sobre \\ El futuro de los Andes
}

Con motivo de los veinticinco años de Allpanchis ofrecemos a nuestros lectores las opiniones de un amplio grupo de especialistas en desarrollo rural, investigadores del mundo andino y agentes pastorales en torno al tema de esta edición especial de aniversario: el futuro de los Andes y de la sierra sur del Perú.

Interesados en destacar y colocar en el debate los hechos, procesos y dimensiones de la vida que sugieren $\circ$ ponen en evidencia potencialidades de desarrollo en los Andes, elaboramos un pequeño cuestionario con las siguientes preguntas:

1. A su juicio, ¿qué futuro es previsible para la sierra sur del Perú en los próximos 25 años?

2. ¿En qué rasgos de la realidad actual sustentaría Ud. la posibilidad de un futuro de bienestar para las poblaciones del Sur Andino?

$\mathrm{He}$ aquí las respuestas. 


\section{Juan Abugattas}

\section{IDS - Instituto de Diálogo y Propuestas}

Al igual que las otras regiones del país, pero de manera más trágica debido a su pasado, el estado de postración en que se encuentra el Sur Andino no tiene más razones que el entrampamiento político en que se debate secularmente el Perú. Hay hambre en medio de valles de inmenso $y$ variado potencial productivo $y$ sequías allí donde abundaban los pastos aptos para la ganadería de camélidos americanos. No hay energía eléctrica alli donde proliferan las caídas de agua y las fuentes de gas natural, y hay incomunicación ahí donde se concentra parte importante de la población del Perú.

Si el Sur Andino se sigue subordinando a la lógica de subdesarrollo y entrampamiento que se impone desde Lima, ciertamente su futuro será una fotocopia del presente. Pero si alcanza una autonomía relativa para aplicar espontáneamente esa misma lógica, su futuro será aún peor.

Un aprovechamiento adecuado de los recursos del Sur Andino exige, a mi juicio, un esfuerzo notable por mejorar la infraestructura, pero sobre todo, una estrategia triple de integración de esa región a 1 . las zonas costeras aledañas; 2. el altiplano boliviano y 3 . el resto del Perú. $\mathrm{El}$ orden numérico quiere corresponder en este caso al de las prioridades que parecen más sensatamente recomendables.

En cuanto a la infraestructura, tres líneas son las más urgentes: las vías de comunicación, las fuentes de energía y las obras de hidráulica, sobre todo para Puno. 


\section{ENTRE PREVISIONES Y POSIBILIDADES}

Pero hay una cuestión previa a decidir, a saber, el modelo de desarrollo urbano y de ocupación del espacio que conviene al Sur Andino. El estilo en que se están desarrollando ciudades como Juliaca y Arequipa, y los destrozos que se están permitiendo en las inmediaciones del Cusco, en especial en el Valle Sagrado, en aras de una supuesta modernización, son claros ejemplos de una estrategia de suicidio. La fealdad es en este caso un indicio de error, que además no se condice en nada con el pretendido respeto al pasado y a las tradiciones.

Es obvio que los valles del Sur Andino no soportan proyectos de urbanización de gran envergadura y que la apuesta en esa zona no debe ser a la limeñización, sino a la creación de centros urbanos medianos, bien diseñados y complementarios entre sí.

Claramente, empero, nada de esto cambiará si no se atiende al principal eje de entrampamiento de la región: la deuda histórica con sus habitantes más numerosos, deuda cuyo pago se exige ahora de la manera menos eficaz y más tradicional: mediante la glorificación del esplendor pasado.

A esta mistificación vale más contraponerle una fuerte autoafirmación en el propio ser. Quien espera ganar respeto no por sí mismo, sino por aquello que perdió o que cree que perdió, es decir, por sus fracasos y carencias, no logrará provocar más que compasión. La clave para un futuro digno en el Sur Andino está pues en el desarrollo de las potencialidades $y$ en la solución creativa de los problemas, cosa que no es posible sin la previa determinación de aplicar de manera inflexible, y sin perder el respeto a las tradiciones, ese atroz lema de los antiguos que recomienda dejar que los muertos lloren $y$ entierren a sus muertos, pues la mistificación excesiva del pasado, lejos de contribuir a forjar una nueva identidad, entorpece las capacidades de acción. La superación de ese entorpecimiento exige coherencia $y$, sobre todo, saber caminar, 


\section{EL FUTURO DE LOS ANDES}

como recomendaban los libertadores $y$ se dice en el hermoso poema de Schiller, a paso de vencedores.

\section{Santiago E. Antúnez de Mayolo R.}

Banco Central de Reserva del Perú

1. En los próximos veinticinco años el progreso y la prosperidad de la patria $y$ en especial el de nuestro sur depende de la actitud de sus dirigentes.

De subsistir la difusión del resentimiento social, la demagogia, el fomento de la lucha de clase como medios para ocupar un cargo público, o la sistemática oposición característica de irresponsables e ignorantes ególatras; el resultado será el de una coyuntura ingobernable en la que la miseria estará estrechamente vinculada a la violencia.

2. En el campo de la persona, estimo que es impostergable un cambio en su formación, cual condición indispensable para el desarrollo y la justicia social.

La educación debe cimentar profundos vínculos familiares en los cuales los padres sepan cómo proteger la salud $y$ fomentar la inteligencia de sus hijos menores de tres años en forma especial.

Requerimos de escuelas donde desde los tres años se desarrolle la mente de los alumnos y el culto a los valores humanos.

La industria y el comercio están estrechamente vinculados a la hidroenergía, gas, vías de comunicación y tecnología de punta que la cortedad de la opinión impide profundizar. 


\section{ENTRE PREVISIONES Y POSIBILIDADES}

Para la prosperidad del sur es indispensable que las llamas, alpacas y vicuñas recuperen sus áreas naturales. Fue $y$ es un absurdo la crianza de ovejas, y aún de vacunos en nuestra serranía.

Hace medio siglo cuando era diputado por mi tierra, Aija, se inició un programa para convertir las faldas de sus cerros en cultivos de plantas medicinales que permitirian al campesino gozar del ingreso que los cultivos del algodón y de la caña proporcionan a los costeños. La revolución del Gral. Odría truncó el proyecto y su laboratorio fue repartido a Huaraz y Lima.

En la agricultura existen muchas opciones, Raimondi decía que de la oca se podría obtener el mejor alcohol del mundo. ¿Por qué no se hace, no obstante que hace dos décadas venimos recordándolo? ¿Por qué no fabricar Vodka con nuestras papas? ¿Por qué no se cultiva el chicuru, cuya exportación incrementaría nuestras reservas en decenas de millones de dólares? ¿Por qué no se hace hojuelas de papa que, deshidratadas al sol y molidas, se emplean como harina?

El mayor nivel de pobreza se halla entre nuestros campesinos en las áreas rurales, debido a que les regateamos el valor de su producción agrícola.

El que nuestros campos de cultivo proporcionen mejores niveles de vida dependerá de que, retomando las técnicas precolombinas, las volvamos a emplear. Entre ellas, las técnicas de:

- Previsión del tiempo: pronósticos de régimen de lluvia, vientos y temperaturas.

- Manejo de agua (antes se usó para sembrar, hoy para cosechar).

- Selección y cultivo del suelo (la microflora del suelo fue cultivada).

- Oportunidad y modalidad de la siembra.

- Procesamiento bioquímico de la semilla (técnica de llakoska y otras).

- Modalidades de fertilización. 


\section{EL FUTURO DE LOS ANDES}

- Técnicas de siembra, cultivo y tratamientos contra pestes y plagas.

- Técnicas de cosecha y procesamiento de semillas. En la carta que en 1539 escribió el Obispo Valverde (el de Cajamarca) al Emperador Carlos $\mathrm{V}$ se lee que sembrado el trigo a la usanza Inca se producía trece toneladas de trigo por hectárea; hoy, al haberse sustituido tal técnica por la hispana, sólo cosechamos la décima parte.

Desde 1973 vengo abogando por el reempleo de la tecnología agrícola precolombina. ¿Alguien desarrollará esta propuesta?

\section{Mario Arrieta Abdalla}

Instituto Latinoamericano de Investigaciones Sociales La Paz, Bolivia

1. La previsión del futuro se asienta siempre sobre datos de la realidad presente, una línea de acciones a realizarse y la cadena de acontecimientos que las influyen y/o las transformaciones que esas mismas acciones van introduciendo. Es, por tanto, un proceso de homeóstasis permanente, del cual sus actuales tendencias más consistentes son las que permitan avanzar visiones prospectivas acerca de sus resultados.

Entre tales tendencias presentes, las que me parecen más significativas se refieren a las consecuencias del doloroso proceso vivido por el Perú -que se inicia con el Plan Inca y concluye con el fenómeno senderista- por el cual, y más allá de las motivaciones subjetivas de sus actores, se produjo el derrumbe del muro que separaba la sierra y a los serranos de las poblaciones y la mentalidad 


\section{ENTRE PREVISIONES Y POSIBILIDADES}

costeña. El señorialista aserto según el cual «el Perú es Lima y Lima el jirón de la Unión" ha perdido cualquier consistencia: es notable el giro dado hacia el "pensamiento andino" por un segmento de la población peruana que, hasta hace unos años, lo consideraba despectivamente.

Relacionado a lo anterior, los modelos de desarrollo adoptados por los países del ahora fenecido tercer mundo, al haberse demostrado tan inalcanzables como los propugnados por el "socialismo real", dejan paso a concepciones más modestas -pero más viables- respecto a otros desarrollos verazmente sostenibles, democráticos y equitativos que, curiosamente, nos remiten a lo mejor del pasado andino.

Creo que es cuestión de tiempo el que la tendencia a la migración hacia las megalópolis se revierta y se produzca un proceso de "recampesinización" sobre bases más estables, sostenibles y democráticas que devuelvan a la sierra andina su antiguo papel de conmutador entre los recursos y las economías del Pacífico y el Atlántico, sólo que proyectado a escala planetaria.

La creciente revalorización de las ventajas de la biodiversidad americana y sus posibilidades económicas futuras corre pareja con la nueva actitud mundial respecto al respeto a la pluriculturalidad y el derecho a la otredad. Llámese postmodernismo, tercera ola o como se quiera, estos son datos de la realidad presente que no pueden dejarse de lado.

Finalmente, en un mundo con una población creciente, los ancestrales patrones andinos de ocupación y uso de suelos, aguas, energías alternativas y recursos naturales cobran una importancia crucial y se revelan mucho más modernos que, por ejemplo, los supuestos de la nefasta "revolución verde».

2. Una de las tendencias más visibles y consistentes de la realidad peruana actual es la del aglutinamiento de países y/o regiones de países en conjuntos socioeconómicos ma- 


\section{EL FUTURO DE LOS ANDES}

yores. Esto significa la (re)constitución de grandes unidades geoeconómicas y socioculturales que le presten otros contenidos al manido concepto de la biodiversidad, extendiéndolo más allá de los recursos ecológicos de fauna y flora para abarcar formaciones antrópicas coherentes.

La creación de los corredores de exportación y de las vías interoceánicas, a despecho de la visión puramente mercantilista que por ahora las impulsa, son un requisito histórico inevitable. Su concreción terminará por disolver esa suerte de compartimento estanco en el que se encerró hasta ahora a las sociedades andinas, constreñidas a una inequitativa relación urbano-rural que las hacía tributarias de las poblaciones intermedias, primero, y de las capitales, después.

Con esto quiero subrayar el carácter integrado o integrador que el espacio andino deberá recuperar en el futuro. Estaríamos ante las puertas de una concepción ampliada del antiguo manejo vertical de pisos ecológicos (y socioeconómicos), potenciado por los recursos científicotécnicos del futuro.

Diluidos los rancios prejuicios señorialistas heredados del coloniaje, la relación urbano-rural en los microespacios andinos podría determinar el potenciamiento de las poblaciones rurales a condición de estar asentadas en la integración (no la segregación) de su entorno campesino. $O$, si se prefiere, el mundo de la producción campesina -diversa, sustentable $y$ con auténticas ventajas comparativas- podría complementarse con los procesos de transformación y agregación de valor que deben desarrollarse en contextos urbanos.

Como toda especulación prospectiva, hace falta señalar algunos requisitos o presupuestos. De manera que, para que el bienestar futuro de las poblaciones andinas pueda concretarse, creo indispensable la consolidación de los principios más profundos de la democracia, empezando por aquel de la igualdad de los productores ante el 


\section{ENTRE PREVISIONES Y POSIBILIDADES}

mercado, base del resto de los derechos a la equidad y el respeto a la diversidad étnico cultural.

En esto juega un papel definitorio la propia identidad y la capacidad de acceder y enriquecer el conocimiento científico y sus aplicaciones técnicas en beneficio de la propia especificidad, tarea que instituciones como Allpanchis han venido realizando desde hace un cuarto de siglo.

\section{Francisco Ballón Aguirre}

\section{Centro de Investigación y Promoción Amazónica}

1. En cierto sentido ningún futuro es previsible. No obstante, las tendencias para el siglo XXI vinculan a la sierra sur con una mayor presencia brasileña y boliviana. Es posible que el empleo del gas de Camisea empate con un reordenamiento en la explotación del oro de Madre de Dios y del cobre de Arequipa, de modo que articulen un proceso de desarrollo limitado en que la oferta de energía redistribuya favorablemente la captación de capitales y la modernización sectorizada. Del tratamiento de variables genéticas y de su velocidad, dependerá la oportunidad de acceso y control de mercados agrícolas suprarregionales. El sur tenderá a especializarse.

Los ejes de crecimiento económico serán los centros mineros y los espacios geopolíticos claves para el comercio internacional, es decir, los puertos del Pacífico y los caminos de entronque con Bolivia, Chile y Brasil.

El sector campesino tenderá a debilitarse como representación de clase, acentuando su pertenencia étnica como un valor definitorio. Es posible también que se 


\section{EL FUTURO DE LOS ANDES}

alteren los mecanismos de confluencia entre un campo más "urbanizado" y una urbe menos subvencionada. La migración campo-ciudad se mantendrá pese a la «modernización" selectiva del agro.

2. El bienestar de las poblaciones del Sur Andino está condicionado a los factores clásicos de la economía y a los «invisibles» de la cultura. De manera que explotación y dominación se presentan simultáneamente. En consecuencia, la redefinición de los roles sociales tipo casta (tan profundamente arraigados) debe conducir a una igualdad en la que las clases sociales se expresen sin la mediación del componente cultural como una "desventaja" (o "ventajan) pre-establecida de un sector sobre otro; en este caso, lo europeo sobre lo andino.

Esto requiere modernización y potenciación de las ventajas ecológico/culturales proyectadas al mercado internacional: empleo de fibras como la vicuña, maíz, semillas $y$ productos agropecuarios, diseños étnicos, etc., etc. Es decir, recoger el valor técnico del pasado y proyectarlo a las condiciones actuales, aprovechando sus ventajas comparativas en manos del sector social que históricamente ha sido su creador.

\section{Miguel Brown}

Agente Pastoral-Sicuani

El progreso del Sur Andino ni será fácil ni gestionado desde afuera. Asegurar un futuro de bienestar para las poblaciones del Sur Andino será una lucha. Debido a los escasos recursos económicos, será necesario que todavía 


\section{ENTRE PREVISIONES Y POSIBILIDADES}

haya apoyo económico de afuera. Sin embargo, la iniciativa tendrá que surgir de la misma población del Sur Andino. A mi parecer, la posibilidad de un futuro de bienestar está en la concertación entre las instituciones públicas y nogubernamentales $y$ las organizaciones populares alrededor de iniciativas puntuales y locales de desarrollo que beneficien al más amplio sector de la población, por ejemplo, electrificación, agua potable, centros educativos, salud y pavimentación de carreteras.

Es obvio que muchas de las organizaciones de las décadas pasadas están debilitadas debido a la crisis económica-política y a sus propios problemas internos, como la falta de democracia verdadera dentro de ellas. Sin embargo, están surgiendo nuevas organizaciones, particularmente al nivel de los barrios y pueblos jóvenes de los crecientes centros urbanos del Sur Andino. El reto es quebrantar la dicotomía tradicional entre el campo y el pueblo y vincular los intereses de las comunidades campesinas con los de los centros urbanos, donde hay más posibilidades de gestionar proyectos de desarrollo.

Creo que también debemos pensar en regiones más manejables y quizás más pequeñas. Las regiones creadas por la Constitución de 1979, con pocas excepciones, no funcionaron. Por ejemplo, la provincia de Espinar se ha beneficiado muy poco al pertenecer al departamento de Cusco. Sus pobladores no han sentido que ello les haya dado más poder para producir los cambios que ven necesarios.

Veo como una señal de esperanza la formación de los frentes únicos de defensa de los intereses de provincias o distritos $y$ los comités de derechos humanos al nivel local. En Espinar, por lo menos, hemos logrado la destitución y detención de un alcalde corrupto y antipopular mediante asambleas populares y reuniones multisectoriales convocadas mayormente por el Frente Unico de Defensa de los Intereses de Espinar. Nuestro reto ahora es canalizar este esfuerzo en la promoción de proyectos de 


\section{EL FUTURO DE LOS ANDES}

desarrollo, como también en garantizar que un porcentaje de la venta de la mina Tintaya beneficie a la provincia de Espinar.

Me parece que la iglesia puede $y$ debe jugar un papel significativo de convocatoria. En Espinar, el Comité de Defensa de los Derechos Humanos fue gestionado por un grupo de la parroquia: "Por la Vida y la Paz», y ahora cuenta con la participación de las instituciones públicas y organizaciones populares del pueblo. En un esfuerzo de concertación, la Secretaría de los Derechos del Niño del Comité de Defensa de los Derechos Humanos recién ha gestionado el primer comedor infantil para niños desnutridos de la provincia de Espinar con la participación de la parroquia, del Centro de Formación Campesina, del Instituto Peruano de Seguridad Social, del ministerio de Salud, de la Unidad de Servicios Educativos y de los clubes de madres. Al nivel del campo, la lglesia tiene un poder de convocatoria impresionante. Hemos de canalizar este poder de convocatoria en favor de proyectos de desarrollo.

\section{Manuel O. Chiriboga}

Asociación Latinoamericana de Organizaciones de Promoción - San José, Costa Rica

Las preguntas planteadas a alguien extraño al sur andino peruano sugieren una serie de reflexiones para el futuro de las sociedades rurales de los Andes en general. Preguntas tanto sobre el futuro previsible como del futuro deseable para los habitantes andinos. Es a partir de ello que intento dar respuesta a las interrogantes del sur andino peruano. 


\section{ENTRE PREVISIONES Y POSIBILIDADES}

Se puede prever algunas tendencias estructurales que continuarán por un tiempo significativo: reducción de la población que vive en las zonas andinas a favor de las regiones más dinámicas de la costa y amazonía. Ello será un resultado tanto de los continuos flujos migratorios, como de la caída en las tasas de fecundidad. Igualmente, es previsible el envejecimiento de la población rural por una migración generacionalmente diferenciada. A ello se vinculará un importante proceso de urbanización en los Andes a favor de centros poblados de pequeño y mediano tamaño. Ello impulsará paulatinamente la diversificación ocupacional desde la agricultura hacia los servicios $y$, en menor medida, hacia la industria.

La actividad agropecuaria seguirá dos caminos en forma simultánea: el afianzamiento de un núcleo de agricultores vinculados a mercados dinámicos, urbanos, 0 al turismo, y una actividad agrícola y crecientemente pecuaria de tipo extensiva, en manos de agricultores(as) a tiempo parcial. La diferenciación provendrá en buena parte de la existencia de rentas diferenciales vinculadas a micro-climas, regadío, calidad de suelos, pero también cercanía a caminos, mercados y comunicaciones en general, así como disponibilidad y accesibilidad a tecnologías. En conjunto los habitantes de los Andes serán menos campesinos y más agricultores, artesanos o empleados.

La pobreza que caracteriza actualmente a una parte significativa de la población del Sur Andino no disminuirá en forma importante, a menos que haya una acción significativa que le sea dirigida. En caso contrario, su proporción estará en buena parte determinada por las lógicas demográficas y la migración.

Los sentidos de la acción social en las sociedades del sur andino peruano se asemejarán con seguridad más a las de Bolivia y Ecuador: el Sur Andino se indigenizará, si entendemos por ello el afianzamiento de una identidad étnica entre la población indígena, de un sentido de diferencia respecto a la sociedad blanca mestiza, fundada 


\section{EL FUTURO DE LOS ANDES}

en el reconocimiento de una herencia común, una cosmología diferente y una lengua propia. Quiero destacar que se trata de un indigenismo moderno, generalmente alfabeto, de poblaciones fuertemente vinculadas al mercado, estructuradas en torno a patrones de diferenciación de clase $y$ no del indigenismo tradicional. Ese indigenismo moderno se afianzará en forma simultánea a la mayor integración al mercado y a la vinculación con la cultura global, no solamente nacional sino también mundial, buscando preservar un sentido de identidad en un mundo cada vez homogeneizado. La diferenciación étnica se volverá simultáneamente un nuevo terreno de negociación social colectiva. La comunidad campesina será cada vez más un elemento crítico para la identidad territorial indígena y menos una forma de organización económica de tipo tradicional.

Las sociedades andinas se desenvolverán cada vez más con lógicas políticas regionales, si entendemos por ello tanto un sentido de identidad territorial y de diferencia respecto a otros centros territoriales, como el afianzamiento de gobiernos $y$ sistemas políticos territorialmente asentados. Es previsible que la acción política regional sea un elemento crítico para la expansión de la ciudadanía. Dicho proceso se afianzará con la urbanización, los cambios socio-ocupacionales y la presión indígenas. Es probable que este sentido regional se proyecte aún a espacios micro regionales, de tipo provincial y municipal. Estas dinámicas presionarán continuamente sobre las dinámicas nacionales.

Los niveles y grados de integración social que caracterizarán a los Andes en el futuro dependerán en buena parte de la consolidación de los actores sociales, económicos, étnicos y políticos en la región andina, así como de la existencia de formas de negociación colectiva. Los gobiernos regionales y municipales, amparados en la descentralización que acompaña a la reestructuración del Estado, deberán jugar un papel crítico en impulsar este 


\section{ENTRE PREVISIONES Y POSIBILIDADES}

nuevo comportamiento social. Su legitimidad en buena parte dependerá de su capacidad de jugar ese rol.

Los ritmos y la velocidad de este proceso dependerán tanto de las propias evoluciones de las sociedades andinas, en donde es posible visualizar ya procesos sociales del tipo señalado, como también del contexto macroeconómico y macro-social, no sólo del Perú sino de toda la región. Un elemento crítico de este proceso será la capacidad del Perú para dirigir hacia el Sur Andino un flujo importante de inversiones, tanto hacia los recursos humanos -educación, salud, etc.- como hacia infraestructura social y productiva. Su efectividad dependerá, sin embargo, de la existencia a nivel regional de formas de concertación y negociación.

\section{Confederación Nacional Agraria}

1. De mantenerse la actual política neo-liberal y centralista, el futuro de la sierra sur de nuestra patria resultaría desalentador.

Confiamos que en los próximos años ocurran cambios sustantivos, que permitan orientar programas promocionales para la actividad agropecuaria, a la que está vinculada la gran mayoría de la población altoandina.

Se requieren inversiones significativas en la infraestructura vial, hidro-energética y de servicios para animar una reconversión productiva agropecuaria. Sólo el Estado podría ejecutar tales inversiones, para lo cual deberá modificarse la política económica. 


\section{EL FUTURO DE LOS ANDES}

2. Se están generando consensos en los diversos sectores políticos, económicos y sociales para orientar inversiones productivas hacia las zonas de mayor pobreza, como el Sur Andino. Inclusive, entidades financieras internacionales como el Banco Interamericano de Desarrollo (BID), Banco Mundial (BM) y la Comunidad Económica Europea (CEE) vienen presionando por la implementación de programas antipobreza.

Hay, de otro lado, un proceso de reconstrucción del tejido social rural, con una propuesta más empresarial productiva, en especial para el manejo pecuario, que alentaría esperanzas de progreso en los próximos 25 años.

Ambos factores, internos $y$ externos, se encaminan a generar empleo permanente, valor agregado a la producción y condiciones de concertación para políticas estables de orden político $y$ social.

Debe recordarse que la estructura productiva agropecuaria es extremadamente frágil en la sierra sur, debido a la oscilación cíclica de las lluvias y la carencia de rentabilidad de la producción.

Al parecer, la actividad de mayor futuro es la ganadería, en particular de camélidos americanos (alpacas). Se ha comenzado programas de repoblamiento, después de las graves pérdidas por la violencia y la sequía. Sin embargo, la rentabilidad de la ganadería para la inmensa población comunera $y$ los pequeños productores está condicionada al valor agregado que se aplique a la lana.

Este es el reto que debemos afrontar en los próximos 25 años. De lo contrario, el futuro seguirá siendo incierto. 


\section{ENTRE PREVISIONES Y POSIBILIDADES}

\section{Mauricio d'Achille} Asociación AMAZONIA

No soy un técnico ni un experto, sino solamente una persona muy interesada en el problema $e$ inquieta por tratar de aportar. Por tanto, tal vez mis razones puedan ser consideradas no lo suficientemente científicas, sin embargo, mis años vividos tanto en la selva como en la sierra me capacitan para tener una razonable visión panorámica.

1. Indudablemente, el futuro a mediano plazo no solamente de la sierra sur, sino de todo los Andes dependerá de decisiones políticas, de voluntad política.

En efecto, la sierra y todas sus riquezas está con los brazos extendidos (como la "pachamama» esperando a sus hijos pródigos).

Algunos programas de retorno migratorio y rehabilitación de andenes están siendo por lo menos tomados en cuenta, y algunos de ellos implementados. Es un buen inicio.

El despoblamiento o abandono de la sierra por causa del terrorismo o la inseguridad, a su vez consecuencias del desinterés del que fueron objeto estas poblaciones, representa por cierto un círculo vicioso que ha venido causando otro impacto en extremo perjudicial: la sobrepoblación de las áreas urbanas. Parece que el espiritu de las «reducciones" españolas ha quedado, de una u otra forma, vigente. No nos olvidemos que al hablar de "progreso" los grupos étnicos nativos tanto de la selva como de la sierra quedaban automáticamente excluidos, como si fueran un «lastre" para el desarrollo.

En mi opinión, hasta ahora las tentativas de rescate de la sierra están, por lo menos, encaminadas. La tarea es enorme, el plazo de mediano para largo. 


\section{EL FUTURO DE LOS ANDES}

2. Tal vez debido a un más profundo sentido de identidad y nacionalismo, así como de autogestión (entendida también como no-dependencia) $y$, porque no, de orgullo de las poblaciones sureñas, la proyección hacia un resurgimiento de los Andes pueda realizarse con mayor celeridad y éxito en esa parte del país.

El factor turístico, puede ser también determinante. Pero eso sí, bien controlado, o sea, teniendo muy en cuenta la capacidad de carga y sobre todo la orientación $y$ educación tanto del visitante como del promotor.

Sin embargo, creo que se debería pensar en la sierra en su totalidad, salvo en aquellas zonas donde, por razones de organización, logística e infraestructura, sería necesaria una sectorización.

En resumen, mi opinión casi incondicional es de un futuro óptimo. El «casi» hace la diferencia, todo dependerá de la voluntad de proceder a recrear condiciones decentes de vida en las zonas rurales y rurales marginales, en lugar de "mejoran las condiciones de los asentamientos "humanos" urbanos.

\section{Francisco d'Alteroche}

\section{Secours Catholique, Francia}

La tierra, su repartición y su explotación deben ser objeto de reformas. El sur del Perú conservará su vocación agrícola y ganadera. El hombre andino del sur es esencialmente rural. Su cultura se afirma alrededor de la tierra y de la vida comunitaria. Pero estos dos factores estrechamente ligados tendrán que ser pensados en un contexto de abertura a una realidad social y económica nueva: la 


\section{ENTRE PREVISIONES Y POSIBILIDADES}

interdependencia de los estados, los movimientos masivos de población y de riquezas.

Una política inteligente de sistema de riego, de reforestación y de electrificación parece urgente.

El drama del sur es la emigración de su población hacia las grandes ciudades o hacia la selva. Sería importante saber utilizar las materias primas que posee el sur para mantener la población en esta zona. No faltan elementos de riqueza (lana, cuero, minerales, turismo, artesanía) para crear pequeñas unidades de trabajo.

Actualmente, el sistema escolar no favorece la preparación del joven para ser creativo y asumir responsabilidades de orden social. Se necesitaría diversificar la enseñanza, de manera que ella capacite en oficios manuales, susceptibles de ser practicados en la zona sur. Preparación también para una mejor capacitación agrícola y ganadera adaptada a la zona.

La sierra sur del Perú padece de un aislamiento geográfico que perjudica su desarrollo. Más que nunca, es necesario crear una red de comunicación que debe facilitar los intercambios y desplazamientos de la población y la salida de los productos de esta zona.

A otro nivel, el mundo andino tiene una gran capacidad de contemplación. Es un mundo orante y de silencio. Veo importante desarrollar más esta capacidad para la riqueza espiritual de la iglesia y del mundo. Hay toda una búsqueda que hacer en este sentido. Hay que ser creativo para no copiar formas de vida contemplativa poco adaptadas a la idiosincracia andina. 


\section{Carlos Iván Degregori}

Instituto de Estudios Peruanos

Quiero antes que nada felicitar a Allpanchis por sus 25 años como publicación indispensable para la reflexión sobre el Sur Andino y el Perú en general.

Por lo complejo del tema, prefiero centrarme en la región de Ayacucho, cuyas zonas rurales he vuelto a visitar durante el presente año después de largo tiempo. La región ha sufrido un cataclismo sólo comparable al de la Conquista o al de la Guerra de Incas contra Chankas siglo y medio antes. Más de cinco mil muertos y $200 \mathrm{mil}$ desplazados; recursos naturales diezmados, amplios espacios abandonados; colapso de servicios básicos ya frágiles como registros civiles, salud $y$, sobre todo, educación; deterioro de la red vial que ha profundizado la desarticulación regional; crecimiento desbordante de la ciudad de Ayacucho y del valle del río Apurímac, donde la depredación ecológica, el cultivo de la coca y el narcotráfico se han generalizado. A esto se suma la destrucción del precario tejido social; la militarización del campo y de la vida cotidiana.

Ante este catálogo de desgracias, cualquiera pensaría encontrar una región postrada, con una población desmoralizada o sumida en una guerra fratricida que escape al control de los actores iniciales del conflicto. Pero no es ni ha sido así. Tras catorce años de guerra no se ha desbordado una "cultura de la violencia" a la colombiana, excepto en parte en las zonas cocaleras. Pero la violencia ha empedrado el camino para la despolitización, el desinterés, el individualismo.

Sin embargo, el clima regional es de un acentuado optimismo, que en diferentes grados atraviesa el conjunto del espectro social y es alentado por la casi desaparición de la violencia política; el retorno de un sector de los 


\section{ENTRE PREVISIONES Y POSIBILIDADES}

desplazados a sus lugares de origen; la recuperación parcial de la actividad agropecuaria, favorecida por un buen año de lluvias; el reinicio del turismo; la reaparición de la inversión estatal, concentrada en el Ministerio de la Presidencia y destinada principalmente a la reconstrucción de carreteras y el reinicio del proyecto de irrigación del río Cachi.

¿Hay razones para el optimismo más allá de la actual coyuntura? ¿Es viable una reconstrucción regional que en los próximos 25 años revierta no sólo el empobrecimiento y la fragmentación sino las grandes diferencias intra $e$ interregionales?

Si se deja todo a la "mano invisible» del mercado, definitivamente no hay futuro posible, salvo la expansión de los cocales $y / 0$ su reemplazo por plantaciones de amapola. La única alternativa distinta es que a nivel nacional se logre en los próximos años una nueva síntesis entre mercado, sociedad civil y Estado, que a partir de una voluntad descentralista logre plantear proyectos regionales viables. Para que lo sean, es necesario reconocer que el porcentaje de población urbana seguirá creciendo y que en las propias zonas rurales ha surgido una irreversible voluntad de urbanización, expresada en la demanda de extensión al campo de servicios como luz y agua potable, $y$ en la elaboración de planos urbanos para pueblos en lugares donde antes se vivía en patrón disperso.

Si la población tiende a ser crecientemente urbana, aparte de los planes de desarrollo agropecuario que deberian incidir en la muy difícil búsqueda de ventajas comparativas de los cultivos y la ganadería altoandinas, es preciso recordar que Ayacucho fue tradicionalmente una ciudad de servicios y que entre los servicios que hoy puede brindar destaca el turismo.

La creación de ejes turísticos como el ya existente Ayacucho-Wari-Quinua-Huanta y otros por crear, como Ayacucho-Vilcashuamán, permitiría valorar la que es posiblemente la más hermosa ciudad andina colonial del Perú 


\section{EL FUTURO DE LOS ANDES}

e incluiría desde la pletórica tradición artesanal huamanguina hasta las ruinas Wari, pasando por el único centro urbano habitado fuera del Cusco donde se superponen la arquitectura Inca y la colonial como es Vilcashuamán, bosques de puyas Raymondi, aguas termales, viejas iglesias $y$ capillas coloniales hoy a punto de derrumbarse. Turismo ecológico, turismo alternativo, turismo puro y simple, deberán ser uno de los pilares de cualquier proyecto que haga de Ayacucho una región viable.

\section{Ponciano del Pino}

\section{Universidad Nacional San Cristobal de Huamanga}

Catorce años de guerra han dejado huellas en la región de Ayacucho. Muchas de ellas con un impacto que se advertirá en los próximos años, definiendo la agenda para el desarrollo regional. Resaltan dos grandes problemas: el desplazamiento y la economía de la coca en un contexto de pobreza extrema y abandono de la economía agraria. Ayacucho fue la región con mayor índice de expulsión y recepción de población desplazada, básicamente rural, por concentrarse en esta zona la mayor espiral de violencia. Este proceso en la actualidad presenta dos posibilidades: la inserción, por un lado, y el retorno, por otro. A contracorriente de las predicciones macroeconómicas, el retorno a la región sub-central es una tendencia dominante. Muchas comunidades en la actualidad vuelven a ser repobladas.

Si bien el gobierno implementó en octubre de 1993 el Programa de Apoyo al Repoblamiento (PAR), éste no ha logrado cubrir mínimamente las expectativas $y$ 


\section{ENTRE PREVISIONES Y POSIBILIDADES}

necesidades de la gente. El retorno exige mayor compromiso e inversión por parte del Estado, como una mayor identificación de la sociedad con el problema.

Por otro lado, la guerra reforzó la producción de la coca y el crecimiento del narcotráfico. El abandono del Estado y la caída de los precios de los productos tradicionales llevó a la población a optar por el cultivo de la hoja de coca, que en la actualidad es el cultivo predominante. Según fuentes de inteligencia, el $80 \%$ de la población del valle del Apurímac estaría vinculada a la producción de la coca sobre una extensión de 20 mil Hás. Ciudades como Ayacucho, que bordean los $130 \mathrm{mil}$ habitantes y no cuentan con inversiones, empresas 0 industrias, se benefician, en cierta medida, con los capitales provenientes del narcotráfico.

$\mathrm{Si}$ bien la guerra deja problemas pendientes, el proceso también presenta nuevas posibilidades. Hay una exigencia desde las bases por participar del progreso y diseñar una economía orientada y articulada al mercado. El énfasis en la inversión, la educación, la carretera y la electrificación está en toda demanda. La población serrana campesina al pasar a ser protagonista de la guerra conquistó el espacio de la política, la ciudadanía y el sentido de Estado. Muy distinta a la realidad de la selva, donde el Estado mantiene una posición más represiva, al intentar destruir sus medios de vida y no proponer $e$ implementar proyectos económicos y productivos alternativos. Esta actitud advierte riesgos, al menos cuando se conoce que esta población luchó desde muy temprano contra Sendero Luminoso y logró acumular no sólo experiencia sino armas con las cuales estaría dispuesta a defender su economía.

Contrariamente a lo que quiso Senciero Luminoso, la guerra aceleró la urbanización de los pueblos, y el campo ahora está más articulado al mercado, estrechándose la relación campo-ciudad. A su vez, las comunidades que a principios de los ' 80 se veían en crisis ahora se 


\section{EL FUTURO DE LOS ANDES}

han reforzado, muchas veces gracias a los comités de autodefensa. Esta nueva estructura política ha permitido reconstruir el tejido comunal y posibilita normar $y$ ordenar nuevamente la vida al interior de la comunidad. Los campesinos dejaron de ser los sumisos de siempre, al advertir sus derechos y tomar conciencia de su ciudadanía. Similar proceso ocurrió con las mujeres organizadas en los clubes de madres. Estos son dos nuevos movimientos que tendrán que ser incorporados en todo proyecto político regional. Síntomas de una forma distinta de reconstrucción de Estado desde abajo, en base a los propios impulsos, motivaciones y necesidades de la sociedad civil rural. A ello se suma la modernización del campo en la visión de progreso de los campesinos. Este proceso puede servir de base para el desarrollo regional de los próximos años. Pero también muchos de los esfuerzos podrían quedar bloqueados si no se reconstituye las bases institucionales $y$ se compromete una fuerte presencia del Estado, con inversiones que ataquen la pobreza de la región y el campo, cuya situación empeoró con los años de violencia.

Una perspectiva incierta, pero con esperanza $y$ posibilidades que se redescubren en las mismas bases luego de los años de terror y violencia. Una invitación a pensar nuevas formas de modernidad y de reconstrucción del Estado desde las mismas bases.

\section{José Estermann}

Agente Pastoral-Cusco

La economía mundial tiende a diversificar la producción y los servicios, en el sentido de transferir cada vez más la 


\section{ENTRE PREVISIONES Y POSIBILIDADES}

producción a los países del sur (por sus bajos costos de producción) y concentrar los servicios en el norte. En este contexto podrá aumentar considerablemente el porcentaje de la ocupación en el hemisferio del sur, pero esto no implicaría un alza importante del nivel de vida.

Los Andes presentan, de un lado, recursos naturales, es decir, materia prima $y$, de otro lado, recursos humanos. En los siguientes 25 años la materia prima va ser reemplazada poco a poco con elaborados artificiales, con el efecto de que la economía mundial dependerá cada vez menos de los proveedores de estos recursos. Una concentración hacia estos recursos (cobre, hierro, gas, etc.) podría resultar muy fatal para el desarrollo de la región. De otro lado, los Andes poseen un gran potencial de recursos naturales en el sentido de medio ambiente $y$ diversidad biológica. La era de los próximos años va ser una época dominada por la preocupación en torno al medio ambiente. En esto existe una gran oportunidad para los Andes, aprovechando de energías alternativas y de un ecoturismo que puede traer un aumento considerable de ingresos $y$, por to tanto, del nivel de vida. Aunque el turismo en sí no es productivo, tiene sus alas productivas y puede ser aprovechado para el mejoramiento de la infraestructura básica de la región.

Con respecto a los recursos humanos, el desarrollo depende mucho de la inversión en educación y formación técnica y ocupacional. No conviene ofrecer un ejército de mano de obra barata, porque esto no contribuye en nada a un despegue. Elevando el nivel general de la formación, y enfatizando algunas especialidades idóneas para la región (ecología, energías alternativas, tecnología adaptada y manejable), los Andes estarían preparados para un progreso factible.

El futuro de los Andes del Perú depende tanto de la economía mundial como de la política del gobierno central, pero de repente más todavía de un despertar democrático y económico de la misma región, sin estrechar 


\section{EL FUTURO DE LOS ANDES}

las manos hacia los de arriba. El espíritu innovador e inventivo de gran parte de los sectores populares en su lucha por la sobrevivencia demuestra un potencial todavía no aprovechado casi en nada.

Esto requiere también una política cultural más allá de un indigenismo nostálgico y de un imperialismo yanqui. El pueblo tiene que encontrar su propio 'sincretismo' cultural, que no frena sino incentiva el desarrollo y el progreso. Ahí también le toca un rol a la Iglesia de los Andes: quitar los obstáculos 'ideológicos' para el despertar y fortalecer un espíritu innovador y esperanzador hacia adelante. No habrá que confundir el Evangelio con ninguna ideología ni identificarlo con una cierta línea política, sino ser más pragmático, concentrándose en el bien del hombre, de donde venga la propuesta libertadora. La riqueza del pueblo (en sus diferentes sentidos) es evidente; falta solamente sacarla del tesoro cuidado celosamente por las diferentes fuerzas de interés. Hay que apostar por la madurez del mismo pueblo y no solamente por sus líderes. La educación necesariamente tiene que implicar un proceso de aprendizaje y práctica democráticos.

\section{Raymundo Finch}

\section{Instituto de Pastoral Andina}

1. El futuro previsible para los próximos 25 años tendría las siguientes características:

a. Crecimiento de las ciudades y pueblos

b. Decrecimiento de la población rural si hay un crecimiento de oportunidades en la ciudad. 


\section{ENTRE PREVISIONES Y POSIBILIDADES}

c. La actividad agropecuaria y la elaboración y transporte de productos no serán suficientes para proveer a las poblaciones crecientes de las ciudades.

d. La población rural tendrá que complementar el ingreso que obtiene de la actividad agropecuaria cada vez más y más con otras actividades: comercio, transporte, etc. La actividad agropecuaria resultará insuficiente para acceder al nivel de vida que desean.

e. Si sigue el proceso actual de desarticulación del tejido social y cultural, el resultado previsible es la destrucción de las leyes y códigos de comportamiento social y cultural, con los problemas de violencia $y$ falta de identidad cultural y social.

f. Si no hay cambios en el modelo y ritmo de desarrollo habrá una pobreza creciente y más profunda, con el crecimiento de los indicadores de pobreza, desempleo, enfermedad, hambre, analfabetismo, violencia doméstica y criminal, etc.

g. Menor influencia y voz de las poblaciones del Sur Andino en la política y cultura nacional.

2. Las posibilidades de un futuro de bienestar se sustentan en la actualidad en los siguientes rasgos:

a. Primeros intentos de formar pequeñas empresas locales, que ven su futuro en el Sur Andino $y$ no en otras partes.

b. Revalorización de tecnologías apropiadas para la región, sean de afuera o sean tradicionales.

c. Conciencia de la necesidad de construir organizaciones locales y regionales: gremios, conexiones comerciales y económicas, redes de comunicación.

Pero el futuro de bienestar para las poblaciones del Sur Andino requiere también de planes y políticas en los siguientes ambitos:

a. De primera necesidad es la construcción de carreteras. 


\section{EL FUTURO DE LOS ANDES}

b. Mejoramiento de la infraestructura productiva, electricidad, agua, comunicaciones, etc.

c. Desarrollo de industrias que generen empleo para la población que sigue creciendo.

d. Mejoramiento del sistema de educación en el Sur Andino en todos los niveles.

e. Importancia de la formación ciudadana para la democracia.

f. Importancia de tomar en cuenta los elementos psico-sociales (identidad, familia, cultura, etc.).

Ahora bien, el futuro del Sur Andino se construirá desde el Sur Andino, a partir de la iniciativa surandina. No caerá desde Lima.

\section{Carlos Flores Lizana}

\section{Agente Pastoral-Cusco}

1. El campo seguirá incorporándose a la sociedad mayor nacional a través de los medios de comunicación social, el transporte, el mercado de mano de obra, etc.

El campesino seguirá migrando a la ceja de selva y selva baja $y$ a las ciudades buscando trabajo $y$ aumentando el sector terciario.

El proceso de mestizaje racial y «lingüístico" se ahondará creando una nueva identidad sui géneris, necesaria de prever y acompañar.

El turismo de todo tipo será un recurso de mucha importancia para el desarrollo y los cambios socio-culturales. 


\section{ENTRE PREVISIONES Y POSIBILIDADES}

2. Los Andes y las comunidades campesinas son un recurso humano y ecológico muy rico y poco conocido. Se debe investigar mucho $y$ bien para poder hacerlas crecer $y$ aportar al país y a la región.

El reto es crear una nueva identidad regional que posibilite un desarrollo económico y ético, sólido y sostenido, y creo que hay bases para ello.

La crisis de lo político puede ser una oportunidad para el diálogo de todos los actores políticos en la tarea de una nueva forma de pensar el país y la región $y$, así, afrontar los problemas de la pobreza, la corrupción, el futuro de los jóvenes y las culturas.

\section{Bernardo Fulcrand} Asociación ARARIWA - Cusco

¿Qué futuro es previsible para la sierra sur del Perú en los próximos 25 años? Pues, iel futuro que le estamos preparando! No veo otra respuesta posible. De otra manera habría que ser futurólogo (manejar esta "ciencia» incierta de la prospectiva, ciega, sorda y a veces estúpida), ser profeta (o sea capaz de romper con lo que se viene haciendo) o utopista (ser capaz de concebir un futuro diferente) para atreverse a pronunciarse sobre el futuro de bienestar para las poblaciones del Sur Andino. Además, convendría indicar aquí que este futuro no puede ser pensado independientemente del futuro de bienestar del resto del país; iEstamos en el mismo barco!..... y ¿qué futuro le espera a Lima?, por ejemplo. Le he dado vueltas a esta pregunta, y me sentía algo ocioso porque distrae de lo más importante: nuestro quehacer, hoy. He tratado de imaginar el futuro en sus 


\section{EL FUTURO DE LOS ANDES}

ambas posibilidades de involución o de progresión, y ninguna me satisface, porque soñaba sólo pesadillas o sueños lenitivos... El futuro en los Andes no puede concebirse simplemente como la repetición del pasado, ni tampoco como una extrapolación a partir del presente; el futuro se aparta tanto del optimismo ingenuo en el que nos quisieron hacer andar ayer como del negro pesimismo que parece teñir nuestros horizontes, hoy. El futuro se debe imaginar, inventar, crear -y por eso es totalmente impredecible- sobre la base de una concepción del hombre y de la sociedad que ponga en tela de juicio las finalidades del sistema hoy imperante. La identidad cultural que tanto nos preocupa, en esta parte del Perú, debe prolongarse en una identidad económica y política. El futuro lo preparamos hoy si nos preocupa la educación, la demografía, el racismo latente en nuestra sociedad, las comunicaciones, los sistemas de producción en zonas difíciles, el manejo de los recursos, etc.

Pero, reducir el futuro posible a la sola previsión tecnológica constituiría una doble perversión:

- El problema del futuro no es: «¿Qué va a suceder?». Esta forma de presentar el problema supondría que se hace abstracción de toda intervención humana. Deberiamos pensar más bien en ¿Cuáles serán las consecuencias que van a desprenderse de tal o cual decisión que tomemos nosotros hoy, sobre las preocupaciones que como hombres y cristianos no podemos dejar de tener? Nos involucra el misterio de la co-creación al que Dios nos asocia.

- Para contestar la pregunta del futuro se tendría que poder contestar, además, la pregunta previa; ¿Cuáles serán las necesidades $y$ deseos de los hombres en esta nueva etapa del desarrollo humano? En su búsqueda de la felicidad, el hombre es ciertamente imprevisible, pero sobre todo ocurrente.

$\mathrm{Ni}$ la simple extrapolación de las curvas de la econometría o de cualquier serie cronológica, ni los cálculos continuistas, ni las proyecciones; ninguna analogía ni modelización podrán anticiparnos el futuro, en los Andes 


\section{ENTRE PREVISIONES Y POSIBILIDADES}

como en ninguna otra parte del mundo. Espero que quienes han formulado esta pregunta no hayan dejado de creer en que, sí, hay futuro en los Andes. Que la proclamación del salmista, preñada de futuro, que hace 25 años el IPA escogió como título de su revista: Allpanchis phuturinqa ("Nuestra tierra dará su fruto" Sal. 85,13 ), no se ponga en tela de juicio hoy al interrogarnos sobre ... el futuro de bienestar previsible para las poblaciones de la sierra sur del Perú.

Al IPA sólo le queda la misión de animar la esperanza de su pueblo, buscando que cada ciudadano sea, hoy, un centro de responsabilidad, de iniciativa y de creación, con todo lo que supone esto de amor $y$ fe en el hermano $y$ en su Dios que lo ha lanzado en esta aventura de crear el futuro.

\section{Percy Flores y Edgar Pebe SEPAR, Huancayo}

1. Nuestro aporte proviene desde la economía institucional $y$ ambiental y se basa en una visión particular sobre el Sur Andino desde la sierra central del Perú. Además centramos nuestra atención en los Andes occidentales del sur del Perú, específicamente las provincias altas de la región Arequipa (La Unión, Condesuyos, Castilla y Caylloma).

Una especial diferenciación de este espacio andino con respecto a la vertiente central $y$ oriental del Sur Andino es que la agricultura se realiza fundamentalmente bajo riego, no existiendo agricultura de secano. De alli que el problema principal presente y futuro sea la insuficiencia 


\section{EL FUTURO DE LOS ANDES}

de agua de riego y de humedad. ¿Cuánto se ha hecho en los últimos 25 años o se piensa hacer en el futuro para solucionar el problema del agua en las provincias altas de Arequipa? Realmente sería muy poco, sino fuera por la loable acción de las instituciones privadas de desarrollo. Aún persistimos en que la solución al problema del minifundio y del agua de riego en Arequipa vendrá de la mano con la ejecución de grandes proyectos tipo Majes. No se ha desarrollado en su debida magnitud la posibilidad que representan los pequeños y medianos proyectos de riego en términos de costos $y$ de impactos en la accidentada topografía altoandina arequipeña. El Proyecto de derivación del río Arma representa una alternativa concreta de solución a los problemas antes mencionados en la provincia de Condesuyos. Sin embargo, dicho proyecto no ha recibido nunca la atención por parte del estado. Se ha preferido siempre concluir Majes, pero ¿a qué costo?

Estando estos dos problemas sin solución, entonces, continuará la tendencia hacia el crecimiento urbano de la ciudad de Arequipa, donde sólo ésta concentra ya el $70 \%$ de la población regional. Esto como resultado de los procesos migratorios tanto de sus provincias altas como de los departamentos de Cusco y Puno. Inclusive los valles costeños como Ocoña, Camaná o Tambo ya no están en capacidad de seguir recibiendo migración de las provincias altas. La aparición de cierto proletariado agrícola permanente en las zonas marginales de dichos valles, así como las técnicas de cosecha de arroz que hacen uso intensivo de la mecanización agrícola no hacen atractivo el proceso migratorio hacia dichos valles. Ahora se prefiere la ciudad. Esto no hace más que constatar la tendencia casi inevitable, que se da también a nivel mundial, del crecimiento de las ciudades por las oportunidades que alli se ofrecen en términos de calidad de vida.

Por otro lado, la región Arequipa tiene otra particularidad: la presencia de monopsonios y grupos de poder. 


\section{ENTRE PREVISIONES Y POSIBILIDADES}

Por ejemplo, tenemos el caso de Michel y la fibra de alpaca. Este es un tema de interés común para la sierra sur del Perú, si tomamos en cuenta la importancia que tiene la producción de la fibra de alpaca en la economía de las familias campesinas de las zonas altoandinas. Entonces, ¿qué hacer? Mientras estos grupos de poder, como es también el caso de la Gloria y la producción de leche fresca en Arequipa, fijen los precios de productos estratégicos, de los cuales dependen gran parte de las economías campesinas, continuará dándose el proceso feroz de descapitalización campesina a través de la explotación vía precios. El actual contexto neoliberal así lo legitima.

2. Es necesario desde ya el desarrollo de una política de carácter redistributivo a través de la reorientación de los grandes proyectos de inversión netamente costa-céntricos que ya existen en la región Arequipa (Majes, Charcani V) a fin de incrementar sus impactos en las zonas altoandinas. Por ejemplo, el proyecto Majes en su fase final contempla la incorporación de 57,000 nuevas hectáreas para el agro arequipeño a través del trasvase de las aguas de los ríos Colca y Apurímac hacia la costa desértica. Actualmente existe el túnel trasandino o Canal de Majes de $100 \mathrm{Km}$. de longitud, diseñado para conducir un caudal de 32 metros cúbicos, que lleva el agua de la provincia de Caylloma, cruzando en su totalidad el valle del Colca, hacia las pampas de Majes-Siguas. Se estima que la inversión en el Proyecto Majes bordea los US\$ 1,500 millones hasta el día de hoy.

¿En qué beneficia un proyecto faraónico de la envergadura de Majes a las poblaciones altoandinas del valle del Colca? Aunque parezca paradójico, el valle del Colca no estuvo contemplado dentro del área de influencia del Proyecto Majes durante su fase de formulación. En 1985 el decidido arrojo del pueblo de Cabanaconde, que pretendió dinamitar el Canal de Majes, obligó a las autoridades regionales a conceder una dotación de agua a 


\section{EI FUTURO DE LOS ANDES}

través de una válvula de salida instalada en dicho canal. A partir de allí, la totalidad de pueblos ubicados en la margen izquierda del valle del Colca, por donde cruza el Canal de Majes, cuenta con sus respectivas válvulas de salida y con esto se ha incrementado la disponibilidad de agua de riego en dicha margen. Las instituciones públicas $y$ privadas que trabajan en el valle han venido ejecutando proyectos de infraestructura de riego a partir de Majes, favoreciendo a 5000 familias usuarias de agua. Además, una ONG local ha demostrado que es técnica y económicamente viable conducir el agua del Canal de Majes hacia la margen derecha, que es la más deficitaria en recurso hídrico, cruzando el cañón del Colca a través de puentes-sifones. Con esto es posible que el Proyecto Majes amplie aún más su área de influencia e impacto en la provincia de Caylloma a través de proyectos de infraestructura menor de riego y de ampliación de la frontera agrícola. Sólo falta voluntad política para hacerlo. Si hemos aprendido esta lección, entonces cuando se construya la red de interconectado Tintaya (Cusco)-Socabaya (Arequipa), que cruzará la parte alta de la provincia de Caylloma, ésta servirá también para la electrificación de dicha provincia y el desarrollo de una agroindustria rural basada en el potencial de recursos productivos existentes en la zona (granos, fibra y carne de alpaca). El caso de Majes es muy similar al Proyecto Choclococha que deriva las aguas de ésta y otras lagunas hacia el desierto de lca y no beneficia en absoluto a las poblaciones de la provincia de Castrovirreyna, en el departamento de Huancavelica.

Existe la posibilidad de que la propia población sea sujeto directo de su propio desarrollo, desde una perspectiva de construcción de ciudadanía, afirmación e identidad cultural y democratización de nuestra sociedad. En las provincias altas de Arequipa, este potencial se manifiesta a través de la existencia y vigencia de «instituciones" y del diseño de propuestas de política de desarrollo. De manera muy general, éstas se definen como el conjunto de reglas 


\section{ENTRE PREVISIONES Y POSIBILIDADES}

que restringen los comportamientos individuales $y$ definen los resultados sociales que se originan de las acciones individuales. Los formuladores de política, por lo general, desconocen $u$ obvian la existencia de «instituciones» económicas y sociales andinas, cayendo sus propuestas en $b$ irreal y fuera de contexto. Tal es el caso, por ejemplo, del nuevo Código de Aguas en el actual escenario neoliberal que pretende solucionarlo todo por la vía del mercado.

En consecuencia, podemos presentar el ejemplo de una institución andina ligada a la gestión de los recursos naturales, como es el "control colectivo del agua de riego". Varios estudios en economía de los recursos naturales han demostrado que dicha institución no responde a factores meramente demográficos, culturales ni legales, sino que responde, dado un ambiente geográfico, a la necesidad de controlar riesgos ligados a las externalidades que se derivan del uso de un bien común o de uso colectivo. Dicha institución es indispensable para la agricultura andina y su desarrollo, ya que garantiza de manera eficiente la reproducción de las poblaciones, y no puede ser sustituida por soluciones individuales $\mathrm{ni}$ de mercado. Además, esta institución perderá legitimidad y vigencia simplemente el día que aparezcan otros tipos de instituciones alternativas que ofrezcan mejores ventajas. Este el caso del "muyuy" (laymi, aynoca) o "control colectivo de la tierra de cultivo" en la zona de Pazos, Tayacaja, Huancavelica. El crecimiento demográfico y el de la demanda alimentaria en las ciudades vía la papa comercial, entre otros factores, han provocado el uso más intensivo de la tierra, razón por la cual no se ha dado la rotación ancestral de las tierras a fin de que recuperen su fertilidad a través del descanso prolongado. Esto ha provocado la desaparición de una institución andina (el muyuy) que en un contexto determinado tuvo legitimidad e importancia vital para el bienestar de las poblaciones andinas. 


\section{EL FUTURO DE LOS ANDES}

\section{Shane Hunt}

\section{Proyecto de Análisis, Planeamiento y Ejecución de Políticas}

No pretendería ser un experto acerca de la Sierra Sur. Sin embargo, puedo ofrecer algunas ideas acerca de la experiencia del desarrollo de regiones análogas en los Estados Unidos, que es el país que más conozco. La experiencia de estas regiones puede sugerir problemas y posibilidades para la Sierra Sur.

Puede parecer sorprendente que tales regiones existan en los Estados Unidos, como por ejemplo los estados de Idaho, Virginia del Oeste, Maine. Estos estados están ubicados, respectivamente, en las Montañas Rocosas cerca al límite con Canadá; en los Montes Apalaches en la región centro-oriental del país, y en el extremo nor-este, también en el límite con Canadá. Estos estados comparten con la Sierra Sur las siguientes características: Son pobres en relación al promedio nacional; son remotos con respecto a los grandes centros del mercado nacional; el progreso económico se hace difícil por ser geográficamente unas regiones montañosas (casos de Idaho y Virginia del Oeste); la economía regional está debilitada por un aparente declinamiento irreversible en los sectores de minería y pesca; la agricultura es frágil y la emigración es crónica.

Lo remoto de los mercados nacionales hace que la industria difícilmente se localice en dichas regiones. Pero si la industria es poco prometedora, la minería y pesca están decayendo y la agricultura es frágil, ¿dónde puede conseguir trabajo la gente joven?, ¿cómo pueden tener esperanzas de recibir un ingreso decente para vivir, sin emigrar?

Cabe recalcar que estos tres estados estadounidenses son prósperos con respecto al promedio peruano. Pero de acuerdo a los patrones estadounidenses son pobres y sus proyectos económicos son poco claros. $\mathrm{El}$ único de los tres 


\section{ENTRE PREVISIONES Y POSIBILIDADES}

que puede encontrar una salvación económica, mediante el turismo de fin de semana, es Maine por su proximidad a algunos centros de mayor población.

En contraste, veo el crecimiento económico de la Sierra Sur con mayores posibilidades que las de estos estados norteamericanos, por tres razones. Primero, los recursos agrícolas son más prometedores. El Altiplano es fértil y las posibilidades para el crecimiento de la ganadería son casi infinitas. Segundo, las oportunidades para el fomento de la producción a través de la inversión y el cambio tecnológico son enormes. Paradójicamente, el gran atraso económico de estas regiones, es a su vez una ventaja para su crecimiento económico. Un tremendo crecimiento económico es posible a través de transferencia tecnológica. Tercero, el turismo tiene gran potencial. Esto comprende en gran medida al turismo internacional más que al de fin de semana. El turismo receptivo del Perú deberá no sólo focalizarse en Cusco y Machu Picchu, sino también incluir otros lugares como el Lago Titicaca y Sillustani como parte del paquete.

Creo que la Sierra Sur, sin embargo, se asemeja a los estados pobres de Estados Unidos en lo siguiente. Primero, la más importante y determinante de las tasas de crecimiento regional es el crecimiento económico nacional. Segundo, la región pobre seguirá siendo pobre en relación al resto del país. Tercero, la emigración continuará siendo significativa. El reto de la política económica regional, entonces, es la de asegurar que si la región pobre no puede igualarse al resto del país, que por lo menos no se quede siempre más atrasada y que también se beneficie del crecimiento económico nacional. Si la política regional no puede lograr al menos esto en una región culturalmente diferente al resto, entonces la comparación no sería adecuada con Idaho, Virginia del Oeste o Maine, sino con Chiapas. 


\section{EL FUTURO DE LOS ANDES}

\section{Bernardo Lindner}

Agente Pastoral-Puno

La palabra «futuro" no puede significar, en este caso, una simple "continuidad en el tiempo". Sin duda, el mundo de los Andes puede permanecer en el tiempo. Lo que está en cuestión es la calidad y perspectiva de vida en esta región.

El reto de "una vida mejor", "con mayor bienestar" para las poblaciones de la sierra sur del Perú tiene que ser ubicado dentro de los desafíos sociales, ecológicos, económicos y políticos existentes hoy a nivel mundial. Los criterios para definir el bienestar de la población del Sur Andino no pueden ser los mismos que están desmoronándose en los países industrializados, donde por lo demás se percibe ya lo nefasto de ciertos niveles de vida y consumo.

Desde el punto de vista de la población de los países industrializados, las respuestas ya están dadas. Después de una época de mucha esperanza en el desarrollo del llamado "tercer mundo", hoy día, ellos perciben que el "sur" no tiene futuro $y$, en ese contexto, mucho menos la sierra "olvidada», marginalizada de nuestro país. Pero ¿quién decide si hay un "futuro en los Andes»?, ¿los países desarrollados?, ¿los limeños? Sin duda la respuesta la tiene la misma población andina. Contrastamos dos posiciones. Clemente Puma, coordinador de la pastoral campesina de Ayaviri, decía en un taller hace dos semanas: "La creación no ha terminado, hay mucho para mejorar. Un campesino sin tierra es como un pájaro sin plumas, condenado a la muerte. Un campesino con tierra tiene mucho por delante, tiene vida, tiene futuro". Otro tipo de respuesta la dan miles de jóvenes campesinos al migrar a las grandes metrópolis de la costa peruana y a las ciudades de la sierra sur, como por ejemplo Juliaca. 


\section{ENTRE PREVISIONES Y POSIBILIDADES}

Para mí, el reto del "futuro de los Andes" pasa por la necesidad de generar un auténtico desarrollo regional. Algunas condiciones básicas se están creando, como por ejemplo la interconexión de Machu Picchu de varios poblados de la zona rural del departamento de Puno con la central eléctrica; los proyectos de asfaltado de carreteras centrales (Juliaca-Cusco, Juliaca-Arequipa). Tener energía a la mano y también vías de comunicación para que puedan salir los productos hace factible cierta rentabilidad para las industrias. Hay que crear todavía otras condiciones.

Veo posible el ufuturo" en: la intensificación de la agricultura y ganadería, sobre todo en cuanto a productos que tienen posibilidades en el mercado regional, nacional e internacional; el aumento del turismo; la formación de la pequeña industria para abastecer la región.

Esas posibilidades exigen necesariamente dos condiciones políticas: 1 . una verdadera descentralización, lo cual permite pensar en un desarrollo regional; 2 . una protección de los productos agrícolas y ganaderos, ante las importaciones a precios artificialmente rebajados.

\section{Waldo Mendoza}

Pontificia Universidad Católica del Perú

1. Es difícil hacer proyecciones para los próximos 25 años de una región como la sierra sur, que ha enfrentado contextos macroeconómicos muy inestables $\in \mathrm{n}$ los últimos años. Por lo tanto, para mis respuestas, supondré que los rasgos más importantes de la actual política liberal se mantendrán durante los próximos años y que la sierra sur seguirá siendo una zona básicamente agraria. 


\section{EL FUTURO DE LOS ANDES}

En este escenario yo diría que, en general, en el país, sobrevivirán aquellas actividades con alta productividad y condiciones naturales que les permitan competir en los mercados. Estos sectores son a mi juicio la minería, sectores de agroexportación y la agricultura de exportación tradicional. Si se acepta esta premisa creo que el destino de la sierra es el de ser un sector cada vez más marginal en términos de aporte al producto, y posiblemente importante en términos de población involucrada y pobreza.

2. Sólo una política de decidida interferencia estatal podría modificar el escenario descrito. Esta intervención, sin embargo, tendrá el gran inconveniente de operar en un contexto macroeconómico que es muy adverso para la agricultura por la falta de mercados para los productos agrícolas tanto en el interior del país como afuera. En consecuencia, la intervención tendrá que ser mucho más eficiente que la del pasado; y necesariamente mucho más masiva, debido a la exclusión que el mecanismo de mercado genera sobre los sectores de baja rentabilidad.

En términos de decisiones políticas creo que la descentralización es la manera más realista de posibilitar el desarrollo agrario $y$, por lo tanto, el de los Andes peruanos.

\section{Luis W. Montoya}

Universidad Nacional Mayor de San Marcos

¿Cómo imaginar el futuro de una de las zonas más pobres, de menor grado de crecimiento económico $y$ estabilidad social, como el Sur Andino, si el actual modelo 


\section{ENTRE PREVISIONES Y POSIBILIDADES}

de desarrollo que se quiere imponer excluye principalmente al grueso de la población campesina? ¿Qué es lo previsible en un escenario donde la violencia siempre ha estado presente $y$ las relaciones sociales de tipo democrático, comunitario, solidario, se han sometido, en la mayoría de las veces, al autoritarismo, al individualismo $y$ a la racionalidad instrumental generados por el desarrollo capitalista? ¿Cuáles podrían ser las posibilidades de alcanzar bienestar y estabilidad relativas si la "modernidad" no permite generar una cultura tolerante y que acepte las diferencias étnicas propias de las poblaciones campesinas del Sur Andino?

Muchuy es una palabra quechua que sirve para designar la carencia de recursos y esperanza, la falta de agua, elemento vital para la agricultura campesina. Muchuy podría ser una palabra que puede servir para resumir el futuro del sur andino peruano, si consideramos, de un lado, la actual intención modernizadora del gobierno que principalmente margina a la población campesina y le resta posibilidades de desarrollo $y$, de otro, los efectos dejados por el proceso de violencia política en las diferentes dimensiones de la vida campesina.

La definición de las relaciones de poder aparece como uno de los primeros fenómenos a considerar en cualquier evaluación que se haga del sur andino peruano. La forma como se ha configurado el poder, el centralismo, la estructura de dominación que ha surgido de los años de violencia y el impacto de las medidas de estabilización económica, se convierten en los procesos centrales a considerar en las proyecciones que se hagan sobre el futuro de esta zona. Es así que los procesos de conformación de clases y los conflictos articulados alrededor de éstas se convertirán en uno de los aspectos centrales en los próximos años; es decir, el conflicto social y la dominación política tienen mucho que ver en las evaluaciones que se hagan sobre el futuro del Sur Andino. 


\section{EL FUTURO DE LOS ANDES}

Se puede asumir el discurso optimista de algunos sectores del capital agrario y mercantil, que promueven la imagen turística y de "orden", junto a la estabilidad social que comienza a vivirse; pero a la vez no se puede negar que siguen presentes los altos niveles de pobreza, el viejo centralismo criollo; las crecientes expectativas culturales de los jóvenes, generadas por la propia modernidad, y la incapacidad del mercado y el estado para brindar salidas a esas expectativas. Lo cual señala el hecho de que existen diferentes imágenes sobre una misma realidad.

El pesimismo que la realidad casi siempre genera no deja lugar a la esperanza, cuando se trata especialmente de vislumbrar el futuro. Pero, a pesar de ello, los rasgos que podrán contribuir decididamente a imaginar el desarrollo $y$ el bienestar de las poblaciones campesinas necesariamente deberán sustentarse en las formas de organización que los propios campesinos generen. Las relaciones de solidaridad han sido, al final de cuentas, los principales mecanismos para sobrevivir que han utilizado los pobres del campo y la ciudad; $y$ ahora se convertirán en los espacios desde donde se recrearán nuevas relaciones sociales, nuevos referentes y códigos culturales, nuevos sentidos de la vida.

Las tradiciones solidarias generadas en las comunidades y rondas campesinas son en cierta forma el espacio esperanzador para imaginar un futuro distinto, $y$ no porque exista una admiración por lo «andino" o lo comunitario, propios de una visión urbana de los Andes que idealiza las relaciones establecidas por su gente, sino porque en estas instituciones encontramos relaciones que cuestionan la racionalidad instrumental $e$ individualista generadas por el capital.

No se trata de levantar un discurso antimoderno. Al contrario, la modernización de las estructuras sociales es un proceso que en este momento «desvanece todo lo sólido en el aire" -usando la frase de Marx, resaltada por Berman-. De lo que se trata es de reconocer que las 


\section{ENTRE PREVISIONES Y POSIBILIDADES}

necesidades de poblaciones como las del Sur Andino, no son cubiertas por la modernización. Más aún, ella genera expectativas, especialmente en los más jóvenes, que ni el mercado ni el Estado pueden luego satisfacer. La marginación de la que son objeto zonas como el Sur Andino contrasta con la integración social que mucha de su gente ha buscado en las últimas décadas, especialmente a través de vías como la educación. Esta situación se refleja igualmente en las relaciones cotidianas, en lo privado, en lo étnico, escenarios que generalmente quieren ser ocultados $y$ excluidos del debate.

Tal vez la situación del Sur Andino se asemeje en algo a la situación que padecían los habitantes del sur italiano en la película de Visconti, Rocco y sus hermanos: marginados por su color de piel, por su cultura, por su forma de hablar, por su pobreza; pero principalmente porque formaban parte de todo aquello que se quería olvidar.

\section{Ismael Muñoz Portugal}

Instituto Bartolomé de Las Casas-Rímac

La historia de los pueblos que habitan los Andes es milenaria, en particular la historia del Sur Andino. Los próximos 25 años serán solamente una pequeña parte de esta larga trayectoria, pero representan un momento crucial para su población. El tiempo actual y el que viene será de una mayor integración de la sierra sur peruana con el altiplano boliviano, zonas del Paraguay y del norte argentino. Las vías que comunican a estos lugares se desarrollan cada vez más aceleradamente $y$ permiten, entre otras 


\section{EL FUTURO DE LOS ANDES}

cosas, el avance del intercambio comercial y de nuevas ideas sobre el progreso económico y social.

Los tratados que se han firmado con los gobiernos de los países que son vecinos o cercanos al Perú, por el lado de nuestro Sur Andino, sólo son una muestra del desarrollo integrador de los pueblos y también de los intereses económicos que conforman esta zona de la América Latina, que ciertamente es un nexo entre dos océanos. El poder acceder tanto a los mercados internos de esta región como a los mercados externos, vía el Océano Pacífico y el Atlántico, explica la mayor velocidad con la que se vienen construyendo carreteras $y$ otros medios de comunicación y transporte. De allí también el gran interés del Brasil de poder salir a nuestro mar a través de la sierra sur peruana.

Para nuestro país, sin embargo, el enorme desafío del futuro es superar la pobreza, y sobre todo la extrema pobreza en que vive buena parte de la población de los Andes. Para lograr ello, el potencial del sur del Perú está en la tradición organizadora de la economía de sus pueblos que les ha permitido resistir $y$ subsistir durante siglos. Las formas propias de enfrentar el reto del medio ambiente $y$ de construir un futuro de desarrollo están, en cierto modo, vivas 0 latentes en estas sociedades. El trabajo colectivo característico de la organización comunal y la posibilidad de incorporar o de gestar tecnologías que dinamicen el progreso de los Andes se hallan presentes en la sierra sur, al estar avanzando el nivel educacional de la juventud y la posibilidad de interactuar con otros centros tecnológicos mundiales.

No obstante ello, dado el modelo económico actual de ajuste estructural aplicado en el Perú desde 1990, la inversión en extracción de recursos primarios será probablemente mayor que la inversión en industrialización de la sierra, lo cual retrasará el desarrollo y excluirá a un buen sector de la población. Sin embargo, el enorme patrimonio monumental, histórico y natural existente en el Sur Andino, 


\section{ENTRE PREVISIONES Y POSIBILIDADES}

principalmente en Cusco y Puno, también harán factible la inversión en servicios vinculados al turismo $y$ en el mejoramiento de la producción agrícola y pecuaria.

De allí que la fuerza y logros descentralistas que muestren tanto los gobiernos locales y regionales, como las organizaciones económicas y sociales de la sierra sur, deberán estar orientados a promover por todos los caminos inversión energética $e$ industrial que posibiliten una ruta transformadora desde el mismo recurso natural $y$, a la vez, fortalezcan núcleos rurales y ciudades intermedias. Junto a ello, una educación que promueva la identidad y autoestima de las personas, y la formación de empresas con responsabilidad sobre su medio ambiente y desarrollo local, tendrán que ser otros dos logros para los próximos 25 años en el país $y$ el Sur Andino.

De esta manera, la contradicción entre un centralismo económico excluyente de las mayorías nacionales y el creciente desarrollo de las expectativas de progreso de la población, ligado al esfuerzo descentralista $e$ integrador de los pueblos de la sierra sur, será la característica que marcará el devenir de los próximos años.

Finalmente, me parece que un pueblo con raíces antiguas como el que vive en los Andes, $y$ que ha enfrentado múltiples desafíos, no puede desesperar sobre su futuro por más compleja que sea su situación en el presente.

\section{Juan Palao Berastain}

Instituto Producir, Puno

Considerando, en particular, los procesos de cambio ocurridos en la sierra del sur del Perú en las últimas tres 


\section{EL FUTURO DE LOS ANDES}

décadas, se puede anotar cambios sustanciales en sus aspectos político, socioeconómicos y culturales, sea por lo estructural o traumático de los hechos o por la apertura que presentan hacia nuevas situaciones.

Así, esta compleja realidad ha transitado desde la propiedad hacendataria de la tierra, con sus implicancias de asedio, usurpación y litigio sobre las comunidades campesinas y parcialidades, hacia una presencia más notoria de la comunidad campesina, pasando por la reforma agraria y la reestructuración de la tierra. De esta manera se desmitifica las caracterizaciones que se hicieron de la comunidad, mostrando sus modos productivos basados en la propiedad familiar de la tierra, así como de los instrumentos, del trabajo y el ganado. El proceso de parcelación irá en aumento: la tecnificación y las acciones de conjunto se basarían en el desarrollo de las unidades familiares dentro del grupo social de la comunidad como marco de pertenencia y realización de actividades, principalmente para servicios.

Los cambios de propiedad de la tierra han posibilitado una nueva perspectiva en cuanto a las opciones políticas en el manejo del poder local, en el que inicialmente tuvieron gravitación las entidades políticas y gremiales. Ahora, estas opciones muestran cada vez mayor preocupación por los aspectos productivos, de comercialización y transformación de la producción agropecuaria.

Las instituciones públicas y privadas han constatado en estas últimas décadas un fracaso bastante alto de sus múltiples propuestas de cambio, lo que las lleva ahora a analizar sus marcos teóricos. De ellas depende ubicarse en la realidad andina y colaborar o participar en el desarrollo de las sociedades andinas.

Como parte del proceso también se observan modificaciones en la actitud hacia los aspectos culturales: como un mayor interés por la educación formal, aún en los niveles técnicos y universitarios, pero mostrando también características que denotan mayor identidad étnica, 


\section{ENTRE PREVISIONES Y POSIBILIDADES}

contrariamente al folklorismo promovido por entidades oficiales. Ese asumir cultural abarca especialmente diversas manifestaciones de ritualidad religiosa, las cuales son realizadas con más frecuencia en el entender de una mayor tolerancia.

En los procesos migratorios, con los intercambios cada vez más frecuentes con la realidad y economía urbana, el poblador rural estaría no solo fortaleciendo la estructura urbana, sino valiéndose de ella para mejorar sus condiciones de vida en su ámbito rural.

Además, el excedente demográfico ha de ubicarse, como ya lo viene haciendo, en las ciudades y pueblos de la zona andina, modificando su fisonomía y rol, generando grupos de gestión regionales que sí posibilitarán la real descentralización y la regionalización.

Considerando lo anteriormente anotado, las economías familiares podrían dinamizarse, así como tener mayor acceso a los servicios, especialmente de educación. Se produciría entonces un proceso de afianzamiento $y$ exteriorización de la identidad cultural, $y$ las relaciones urbano rurales conllevarian a consolidar una conciencia regional andina en los emergentes grupos productivos en cada ciudad del área. Todo ello ha de posibilitar condiciones para el mejoramiento de las cualidades de vida para la población del Sur Andino.

\section{Abdón Palomino Meneses}

Antiguo coordinador de edición de Allpanchis

Cuando en 1969 se proyectaba y se realizaba la edición de Allpanchis Phuturinqa, revista del IPA, se per- 


\section{EL FUTURO DE LOS ANDES}

filaba una idea que, ahora a más de dos décadas, sigue siendo válida $y$ pertinente: conocer el alma del hombre andino y sus ingentes potencialidades para ser, él mismo, constructor de su vida y de su destino. Cómo no recordar a Lucho Dalle repitiendo $e$ insistiendo esta idea a los agentes pastorales, muchos de ellos foráneos y con muchas dificultades para captar y penetrar la peculiaridad de estos hombres de largo pasado y de grandes esperanzas. Pero las resistencias se daban también en los nacionales, perplejos ante el giro de la pastoral a partir del Vaticano II y la Conferencia Episcopal Latinoamericana reunida en Medellín.

Los andinos exhiben un pasado largo, bullente, sui géneris y con características que los hacen semejantes a otras viejas culturas de "larga duración» del mundo. Su apego a la tierra, su acervo tecnológico, sus cultivos, su profunda religiosidad, "inscrita en su propia cosmovisión" (Allpanchis, nro. 3), su medicina y todas sus demás expresiones culturales muestran permanencias $y$ persistencias que la presencia avasalladora de Occidente desde el siglo XVI y la modernización actual no logran desarraigar.

Algo que en la vivencia de los andinos es tercamente persistente, por lo mismo que no ha podido ser anulado por el individualismo de la modernidad, es el sentido -diría, mejor, la práctica vital- de la solidaridad. El hombre andino no teoriza sobre ella, simplemente la practica de manera cotidiana. Las comunidades campesinas andinas están hechas de solidaridad, exactamente lo contrario del "sálvese quien pueda» de las sociedades "desarrolladas».

Entre las permanencias del mundo andino constatamos hoy sus aportes a la alimentación mundial. ¿Cuántos y qué calidad de productos es posible encontrar cotidianamente $y$ de modo insustituible, en la mesa de las sociedades y países satisfechos? La papa, uno de ellos, es domesticada gracias a una ingeniería genética incomparable 


\section{ENTRE PREVISIONES Y POSIBILIDADES}

y cultivada en sorprendentes nichos ecológicos de los Andes.

Los Andes no han muerto. Su cultura y su vitalidad exhiben solidez y permanencia. Los sucesivos intentos de arrastrarlo hacia la «civilización occidental y cristiana" o al paraíso mercantilista moderno no podrán ser exitosos mientras los andinos ejerzan el derecho a ser distintos $y$ ser ellos mismos. El apego a su identidad les ha permitido. superar el estigma de «inferior raza india» constantemente exhibido por los portadores de la civilización de ultramar.

Empero, esto no significa que el andino sea un universo cerrado e impenetrable custodio de sus tecnologías y valores. Siendo un pueblo vitalmente agrícola y celebrante, ha sabido incorporar con pragmatismo cosas y valores foráneos. Por ejemplo, muchos cultivos europeos y asiáticos, ya andinizados, es decir, adaptados a las condiciones peculiares de los Andes, constituyen la base de su subsistencia.

En esa medida, su futuro a mediano y largo plazo dependerá de cómo logra seguir persistiendo en sus tecnologías $y$ en su modo propio de ver y relacionarse con su mundo. Pero, al mismo tiempo, de cómo va incorporando lo occidental sin dejarse absorber.

Sin embargo, es preciso no subestimar la penetración altamente corrosiva de la modernización. En la medida en que el mercantilismo no concibe sectores marginales a su dinámica de mercado, querrá "modernizarlo", es decir, hacerlo sujeto activo de la oferta y la demanda, introducirlo al mundo de los fertilizantes, de la producción comercial, de los insumos químicos, de la maximización de los beneficios monetarios.

¿Es esta modernidad la que se adecúa a la cosmovisión, a las condiciones geográficas y productivas del hombre y la mujer de los Andes? Objetivamente, no.

Conservar su identidad, incorporando creativamente los aportes de la modernidad, constituirá el fundamento de 
EL FUTURO DE LOS ANDES

su ser él mismo, en un mundo que cambia vertiginosamente $y$ no precisamente en esta dirección.

\section{José Pérez Mundaca}

Universidad Nacional de Cajamarca

En términos de desarrollo, en los próximos 25 años, dos tipos de factores de distinto signo interactuarán contrapuestos entre sí en la sierra sur del Perú. Uno constituido por factores negativos $y$ otro por factores positivos.

La persistencia del centralismo con base en Lima en detrimento del interior y su reproducción en los espacios regionales, privilegiando a las capitales departamentales en menoscabo de las provincias $y$ distritos $y$, sobre todo, de la población rural; la posibilidad de una sobreexplotación irracional de los recursos asociada a la extrema pobreza, de un despoblamiento de zonas rurales a partir de la tendencia a una desmesurada emigración campesina con destino a ciudades intermedias de la misma sierra sur; las restricciones a nivel de la inversión social por parte del Estado en el campo; y la focalización de la gran inversión privada nacional y extranacional en la explotación de recursos minero-energéticos, sin mayor impacto en la generación de puestos de trabajo, son factores de signo negativo con probabilidad de persistir en los próximos lustros.

La tendencia al afianzamiento de los mercados regionales fundada en una actividad comercial con sustento agropecuario; el fomento de pequeñas $y$ medianas irrigaciones, de la industria sin chimenea (turismo), de una cultura conservacionista que se apoya en la preservación 


\section{ENTRE PREVISIONES Y POSIBILIDADES}

del medio ambiente, de una producción artesanal y de una cultura empresarial que posibilite $y$ facilite la instalación de pequeñas industrias de transformación agropecuaria con base en productos locales y con miras a la eficiencia; la lucha regional por una mayor participación en las ganancias que generará la explotación minera y energética, son factores de signo positivo que, sin duda, prevalecerán sobre aquellos de signo contrario, y devendrán en pilares fundamentales del desarrollo de la sierra sur en los próximos 25 años.

Pero el recurso fundamental para el desarrollo de esta parte del país es evidentemente su población rural organizada: sus comunidades campesinas. No conozco mucho la sierra sur. $\mathrm{Mi}$ inquietud intelectual ha estado centrada más bien en la sierra norte, en el estudio de la violencia y de la organización social, particularmente de las rondas campesinas. La minería (Yanacocha y La Granja) y la producción agropecuaria (especialmente leche) son recursos vitales para el desarrollo de Cajamarca en la sierra norte. Pero ni la minería ni la actividad agropecuaria tienen la calidad de las rondas campesinas, que en los últimos años han devenido en el recurso central en que descansa y descansará el desarrollo de Cajamarca en los próximos años.

Las comunidades campesinas de la sierra sur, que traducen el despliegue de esfuerzos individuales en provecho del bienestar colectivo de los campesinos, tendrán plena vigencia en los próximos 25 años, presionarán para tener una mayor inserción en la vida política regional y del país, en un marco temporal que paulatinamente será menos reacio a estas aspiraciones, tendrán un mayor acceso a la educación y a la ciudadanía, y en un contexto regional signado por la persistencia de prácticas sociales solidarias que, a despecho de la ola neo-liberal que caracteriza a la presente coyuntura y que, ineludiblemente, irá desvaneciéndose en un futuro más bien próximo, 


\section{EL FUTURO DE LOS ANDES}

aumentarán su peso específico como factores centrales del desarrollo de la sierra sur del país.

\section{Bruno Revesz}

Centro de Investigación y Promoción del

Campesinado - Piura

Todavía no está seca la tinta del desafortunado Acuerdo Municipal del Qosqo de setiembre último por el cual su Alcalde, reaccionando en contra de una entrevista publicada en El Comercio, retiró la medalla de la ciudad y declaró "persona no grata" al director de una ONG que ha dedicado durante 20 años lo principal de su actividad a un mayor conocimiento de la realidad andina. La opinión, así censurada, se atrevía a sostener que los Andes podrían "ser al Perú lo que Africa es al mundo", una entidad de poco peso comercial $y$, por ende, de reducido interés estratégico para el futuro.

Una afirmación de este tipo puede, en el caso de los Andes peruanos, respaldarse en las mediciones cuantitativas del decrecimiento relativo de la población y del PBI de los departamentos de la sierra frente al crecimiento nacional. No tendría la misma pertinencia en otras regiones del mundo andino: Colombia, por ejemplo, en donde el perímetro de la riqueza y de la productividad encierra a las tres cordilleras $y$ a los dos valles interandinos del Cauca y del Magdalena, y donde reinan seguros de sí Cali, Bogotá y Medellín, mientras que la costa pacífica queda relegada; o Bolivia a pesar de la importancia creciente del agro-business de Santa Cruz.

En otras palabras, Qosqo no es más el ombligo del mundo, ni siquiera del Perú. Mas, a pesar de ser el 


\section{ENTRE PREVISIONES Y POSIBILIDADES}

arca de agua del país, de disponer de una sobresaliente diversidad fito-genética y de proporcionar por sus exportaciones mineras las divisas que sustentan el consumo y la modernización urbano-industrial de Lima, el curso actual de los Andes peruanos parece evocar la posición estructural de otras regiones amenazadas de marginalización económica por nuevos centros de acumulación: el desolado noroeste brasileño desplazado por el triángulo de oro de Sao Paulo-RíoBello Horizonte o la parte meridional de Italia que inspiró a Gramsci sús reflexiones sobre el bloque histórico del Mezzogiono y que motiva hoy la movilización en su contra de las ligas lombardas.

En este contexto el futuro de la sierra peruana dependerá estrechamente de cómo nuestra colectividad política sepa asociar desarrollo, equidad e integración en términos económicos, sociales, culturales y geopolíticos, contrarrestando la tendencia actual a la litoralización y a la metropolización del país.

Varios factores incitan a avanzar decididamente en esta dirección:

a. La andinización del país como fortalecimiento de la identidad nacional. En el conocimiento en primer lugar: no olvidemos que a principios de siglo las pioneras incursiones geo-históricas de Riva-Agüero parecían todavía exóticas a los de su clase y que, por valiosas que hayan sido, las percepciones de Haya de la Torre y de Mariátegui son algo borrosas frente al saber de muchísimos técnicos, profesionales, políticos y científicos sociales que egresan de la universidad hoy día. En el terreno más que todo: en la metamorfosis de Lima (a la cual se añade la penetración de la ceja de selva) la movilidad de lo andino ha puesto simultáneamente en jaque nuestro sistema representativo, ha desplazado y relativizado las fronteras de lo étnico $y$ ha establecido nuevos lazos vitales con el interior del país. 


\section{EL FUTURO DE LOS ANDES}

b. El surgimiento de la necesidad de la descentralización política y territorial como hito de la modernización y de la modernidad. Economía abierta y sociedad abierta pasan por el reforzamiento de la autonomía y de la gestión municipal de la red de ciudades intermedias, el incremento drástico de la capacidad de decisión y de inversión de los gobiernos regionales, la interacción entre agentes públicos y privados y la apertura de espacios de debates y concertación para la organización de las sociedades civiles regionales. Sin un nuevo marco institucional no es concebible la expansión económica de la sierra.

c. Los efectos inducidos por la globalización: ésta no se reduce a la competitividad en el mercado internacional, a la transferencia de tecnologías o a la difusión de modelos de consumo, sino que propicia una mayor adhesión a las normas contemporáneas de la democratización como esfuerzo plural, de la educación y salud ciudadana, del bienestar y de la integración social, y significa también una mayor interdependencia de los particularismos.

d. El carácter no dramatizado de nuestro multiculturalismo: a diferencia de la violencia identidaria que emerge en determinadas áreas de Europa del este, de Africa o de las sociedades islámicas, la apropiación progresiva de los derechos humanos no se cristaliza aquí en comunidades excluyentes y hostiles. Es signo de que se puede lograr la convivencia y luchar contra el deterioro social; es signo también de que nuestra apuesta por el futuro puede inspirarse más en los sueños bolivarianos de integración andina y latinoamericana que en la nostalgia de los imperios y de los virreinatos de ayer, más en la creación que en la preservación y la conservación. Es un recurso invalorable para el futuro de los Andes $y$ de América Latina que sea posible un enriquecimiento por el intercambio y la confrontación de las diferencias que se generan hoy, abriéndonos las puertas de una integración creativa y la posibilidad de una cooperación de las voluntades. 


\section{ENTRE PREVISIONES Y POSIBILIDADES}

\section{Franz Riedel}

Proyecto de Apoyo Comunitario-Sicuani

Considerando que en los últimos 25 años el campesino de la sierra sur ha vivido una mayor pobreza y la pérdida de su capital agropecuario en comparación a su situación de 1969, es algo difícil y atrevido pronosticar un futuro de bienestar para los próximos 25 años, y peor aún si sigue la corriente del neoliberalismo que favorece a unos pocos a costa de las grandes mayorías. Sin embargo, en la actualidad hay algunos indicios que nutren la esperanza $y$ las posibilidades de que para el año 2020 cambien favorablemente algunas de las condiciones de vida del poblador de la sierra sur.

En primer lugar, veo un cambio de mentalidad principalmente en el campesino joven, sus estudios, aunque deficientes, especialmente los técnicos superiores, y algunas experiencias de trabajo en otras partes del país le han abierto horizontes que los mueven a nuevos y más eficientes compromisos en la comunidad. La experiencia con jóvenes técnicos agropecuarios y miles de jóvenes comuneros en las provincias altas de Cusco desde el Programa de Empleo Juvenil (PEJ) muestra que el joven campesino está en condiciones de buscar una alternativa propia no sólo productiva sino social y política, reflexionando $y$ experimentando sus propias formas organizativas $y$ apostando por su permanencia en la zona como productores eficientes sin buscar solución a través de la migración.

La educación formal, ajena a la realidad de los niños y jóvenes, alienante respecto a sus necesidades, no es, por cierto, la única experiencia formativa. La vida, la pobreza, la respuesta destructiva del terrorismo, el abandono del campo y de la juventud por los gobiernos de turno $y$ sus propias luchas por trabajo $y$ un futuro mejor, 


\section{EL FUTURO DE LOS ANDES}

enseñan a los jóvenes a rescatar sus valores y apostar con creatividad por su futuro. Este recurso humano que se potencia que empieza a jugar un rol de liderazgo cada vez más importante en las comunidades de la sierra sur, garantiza cambios positivos en el futuro próximo. ¿Y qué decir de los niños que recién están naciendo y que en 25 años tienen mucho que decir $y$ hacer?

Como segundo factor veo que tanto el campesino como muchas instituciones colaboradoras tienen cada vez más una visión de desarrollo que están promoviendo desde sus recursos $y$ con sus posibilidades, aunque también buscando apoyo económico y técnico de instancias públicas $y$ privadas. $Y$ lo interesante en su planteamiento es que, tanto por deficiencias económicas como por exigencias ecológicas, están impulsando ya un desarrollo con tecnologías más apropiadas, por ejemplo, en el manejo de los recursos suelo y agua, en la fertilización con abonos orgánicos, en el control biológico de plagas y enfermedades de los cultivos, en la aplicación de la medicina natural en humanos $y$ animales, etc., protegiendo de esta manera a la madre tierra, manteniendo el equilibrio del medio ambiente $e$, inclusive, produciendo con mayor eficiencia $y$ rendimiento. Se empieza a pensar en nuevos paradigmas de desarrollo, ya que el "desarrollo occidental» o del norte ha llegado a sus límites amenazando incluso con la destrucción del ser humano y de todo el planeta. Se busca un desarrollo sostenido que no agote los recursos, que mantenga el equilibrio en la naturaleza, que no busque rentabilidad $y$ utilidad económica a corto plazo $y$ a todo costo, en desmedro de la humanidad, que no divida a los hombres en unos pocos ricos y una creciente mayoría de pobres que apenas pueden sobrevivir.

Si estas tendencias se hacen extensivas y sistemáticas en el sur del Ande, empezando desde las experiencias del enfoque sistémico de cuencas hasta nuevas formas de participación y organización más democráticas en la producción, transformación, comercialización $e$, inclusive de 


\section{ENTRE PREVISIONES Y POSIBILIDADES}

consumo, tendrán una influencia positiva sobre las políticas regionales y nacional.

Como tercer aspecto considero la cultura andina $y$ su visión holística del universo como un potencial importante para un desarrollo sostenible y humano. La finalidad del desarrollo debe ser $y$ es el hombre, su bienestar $y$ felicidad, la que no se logra sólo con una mayor producción y economía -menos una economía desigual y de desigualdades- sino con sistemas de convivencia con la naturaleza de la que dependemos, conformes con nosotros mismos como personas sanas, en armonía y solidaridad con nuestros semejantes y con Dios y el mundo religioso. Que digan algunos que estos son paradigmas de sociedades atrasadas. Deplorablemente, no ven $o$, interesadamente, no quieren ver que la llamada modernidad $y$ todos sus impresionantes avances técnicos no sólo están amenazando con hacer retroceder a la especie humana a la edad de la piedra sino con la extinción de todo signo de vida en la tierra.

Los avances científicos deben elevar al hombre a mayores conocimientos y una visión más amplia $y$ profunda del universo y a una vida más plena, satisfecha y feliz. $Y$ no reducirlo a un pobre $y$ pasivo consumidor manipulado $y$ explotado por intereses de unos pocos en el mundo.

La cosmovisión integral andina y los resultados más avanzados en las ciencias naturales sobre una visión holográfica del universo tienen muchas coincidencias que tenemos $y$ podemos rescatar para que todos los valores humanos, solidarios, naturales y religiosos-culturales transciendan en la creación de un mundo mejor de mañana.

En resumen: potenciar el recurso humano desde su niñez y juventud, los recursos de la naturaleza como algo vivo (la madre tierra) con la que el hombre se relaciona, y las raíces de una cultura con su cosmovisión holística 


\section{EL FUTURO DE LOS ANDES}

significarian un desarrollo integral para los próximos 25 años, $y$ no sólo en el Sur Andino.

\section{Linda J. Seligmann George Mason University - Virginia}

Los antropólogos alegan no estar en posición de leer el futuro en bolas de cristal. Eso pudiera ser una virtud, dadas las predicciones de los economistas, parecidas a los informes matinales sobre el tiempo. Yo sostendría, sin embargo, que el hecho de que trabajamos sobre el terreno, con sentido del contexto histórico, nos permite, como lo dice Clifford Geertz: «intuir los significados, evaluar las intuiciones $y$ extraer conclusiones explicativas de las mejores intuiciones".

La zona sur andina, en los últimos 25 años, ha sido un campo de batalla para la democracia, los derechos humanos $y$ el bienestar económico, en particular para los pueblos quechuas. Si se toma cada una de estas áreas, hay razones para pensar que en el próximo cuarto de siglo serán un área para la experimentación política y económica. Mientras el NAFTA empiece a hacerse sentir, los países andinos pueden embarcarse, una vez más, en el intento de crear un bloque económico-político para desarrollar, eventualmente, un tratado de libre comercio. Este bloque puede acrecentar el empleo y estimular la economía. También podría deprimir los salarios y crear condiciones sin precedente de dependencia económica y política.

Los experimentos en el ecoturismo y el desarrollo sustentable pueden ampliarse. Creo que la cuestión de los 


\section{ENTRE PREVISIONES Y POSIBILIDADES}

derechos sobre las patentes de los recursos genéticos en plantas, por ejemplo, que podrían resultar invalorables para el mundo desarrollado, preocupará crecientemente a los pueblos indígenas que deseen proteger sus derechos. El interés del mundo occidental en la medicina $y$ el conocimiento de las plantas que tienen los indígenas ha crecido exponencialmente a partir de la decisión del Instituto Nacional de Salud de establecer una sección para la medicina no-tradicional.

De una manera más oscura, las zonas aitas ya se han convertido en escenario para las inversiones, especialmente en la extracción de minerales. Mientras que por un lado mejoran la eficiencia y la competitividad y proporcionan una fuente inmediata para el intercambio internacional y el empleo, estas políticas pueden tener serias consecuencias para el medio ambiente, dejar detrás una infraestructura inútil, gigantescos huecos en el suelo, e inclusive grandes masas de desempleados migrantes entre quienes hayan llegado a esas zonas buscando fortuna.

Refiriéndonos a asuntos relativos al proceso democrático, las campañas recientes muestran un alejamiento de los partidos políticos tradicionales. Los movimientos de base y las organizaciones no-gubernamentales a menudo sintonizan mejor con las redes flexibles que constituyen las comunidades $y$ las federaciones $y$ que vinculan a las ciudades con el campo. Creo que estos movimientos $y$ organizaciones continuarán creciendo y los pueblos de los Andes del sur deben procurar desarrollarlos $y$ afirmarlos para lograr un mayor control sobre ellos. Actualmente, muchas de las ONGs no son responsables ante nadie. Creo que las mujeres jugarán un papel más activo, formal $e$ informalmente, en política; accederán en números mayores a puestos de importancia; $y$ pueden prestar más atención a las demandas para mejorar los servicios de salud, educación $y$ otros. De otro lado, tengo dudas de que los líderes indígenas puedan representar en un futuro próximo a sus pueblos en puestos de importancia. 


\section{EL FUTURO DE LOS ANDES}

Las redes peculiares de migrantes que se desplazan entre los valles $y$ que bajan ora a la costa, ora hacia la selva, constituyen bases importantes para la forja de la identidad quechua. La palabra «cholificación" no significa necesariamente movilidad hacia arriba o asimilación al tipo de vida mestizo, ni es una categoría étnica cosificada; es por el contrario un proceso de construcción social que todavía no ha sido suficientemente sentido y con el cual los peruanos tendrán que lidiar de manera creciente. Este "proceso" significa también un poder cultural alimentado por la heterogeneidad de las gentes, lugares y valores de los que se sirve el pueblo quechua, adaptándolos, adoptándolos, imitándolos, moldeándolos, rechazándolos y asumiéndolos.

Los rezagos de la violencia -del mundo oficial y sus compañeros, la corrupción, los regímenes y movimientos autoritarios, la imposición militar y policial- apenas si están ocultos. Creo que los peruanos son, y continuarán siendo, más suspicaces respecto de todo eso que antes. Sin embargo, queda por verse cómo puede canalizarse todo este escepticismo constructivamente en la producción de soluciones políticas que ayuden a resolver las necesidades de una sociedad atravesada por la discriminación de clase y étnica, discriminación que está siendo exacerbada por las políticas neoliberales y tentada por la industria de la cocaína.

Tal vez uno de los problemas más urgentes que el Perú enfrenta es la necesidad de lograr una autosuficiencia agrícola en muchísimo mayor medida que lo que es el caso hoy en día. Creo que tendrá que pasar mucho tiempo hasta que la expansión de la industria, especialmente en las alturas sur andinas, cree suficientes empleos como para acomodar a todos los que migran hacia las áreas urbanas, especialmente capitales departamentales, en búsqueda de educación $o$ huyendo de las presiones demográficas generadas sobre sus terrenos o escapando de las dificultades de la vida rural. La autosuficiencia agrícola 


\section{ENTRE PREVISIONES Y POSIBILIDADES}

no podrá alcanzarse sin algunos forcejeos. Se requiere extender el crédito a un número mayor de personas. Las oficinas gubernamentales deben hacerse más asequibles a los campesinos. Los incentivos para incrementar la producción deberán incluir, por ejemplo, el establecimiento de mercados regionales, medios de transporte decentes $y$, tal vez, algunas industrias pequeñas dotadas de tecnología apropiada.

Habiendo dicho todo esto, yo preveo una ruta difícil, inestable para los pueblos de la región sur andina, que los obligará a seguir luchando por sus derechos económicos y políticos, valiéndose de la resistencia y flexibilidad de su extensa red de vínculos sociales y su perspicacia respecto del funcionamiento de los grupos de interés, las ONGs, las campañas electorales, las organizaciones políticas y los esfuerzos de movilización política.

\section{Alberto Sacio León}

Fundación Perú

1. Que el futuro de la Sierra Sur del Perú sea uno de bienestar dentro de 25 años, depende de las acciones que se tomen en el presente inmediato $y$ de que ellas se continúen llevando a cabo en forma permanente y con creciente intensidad a través de todo ese tiempo.

2. Prácticamente no existen urasgos de la realidad actual» que sustenten "la posibilidad de un futuro de bienestar para las poblaciones del Sur Andino" si no se establecen $y$ se llevan a cabo, en forma consistente, politicas diferentes a las que se han venido aplicando por muchos años. 


\section{EL FUTURO DE LOS ANDES}

3. La primera acción -que es la más urgente y sin la cual no habría progreso- es la de una política educativa adecuada para ese medio.

La educación primaria es la más importante para lograr un despegue en las zonas rurales sur andinas.

La razón de la bajísima productividad en esta región se debe principalmente al hecho de que alli se encuentra el mayor número de analfabetos $y$, más aún, el mayor número de iletrados funcionales. El descuido en la educación de la mujer es muy grave en la sierra, en general, $y$ en el sur, en particular. Al no estar educada la mujer, no se educan los hijos, pues es la mujer la que generalmente acompaña $y$ educa a los niños en sus primeros años, que son los formativos.

$\mathrm{Si}$ el niño no recibe en el hogar entre los 2 y 5 años nociones básicas de economía, de ecología y salud, no va a estar bien preparado para ganarse la vida en el medio rural en que se desenvuelve, aunque más adelante las reciba.

4. El sur y el medio rural están íntimamente ligados Con la excepción de Arequipa, no hay en el Sur Andino concentraciones de población $y$ de inversión que hayan desarrollado una industria manufacturera eficiente que dé empleo abundante con ingresos más adecuados.

El problema agrario es grave. Cuando se hizo la Reforma Agraria, la ley -con bastante buena visión- estableció los dos problemas fundamentales del agro; $1^{\circ}$ el minifundio que ocupa las $3 / 4$ de la tierra cultivable y $2^{\circ}$ la concentración del resto en manos del gamonalismo. En el ámbito ganadero la situación es muy similar, excepto que por la falta de lluvias y de manejo, las extensiones necesarias para la sobrevivencia del dueño son mucho mayores.

La reforma olvidó por completo el primer problema, que es el del minifundio. En la actualidad -como lo comprobará el Censo Agropecuario en ejecución- del $70 \%$ de la tierra en situación de minifundio (según el Censo 


\section{ENTRE PREVISIONES Y POSIBILIDADES}

Agropecuario de 1972), debemos de haber pasado a $85-90 \%$ de la tierra cultivada en esa situación.

5. El colectivismo en el agro no ha funcionado en ningún país en el mundo. Cuando Stalin lo implantó en Rusia, sembró las semillas de la destrucción de ese imperio. La gran masa del pueblo del Perú contempló impertérrito la destrucción de la élite dominante Inca a principios del siglo XVI por un puñado de conquistadores; no tenían realmente nada suyo que defender. Las SAIS, cooperativas y comunidades han fracasado casi por completo en iniciar el cambio hacia el bienestar.

6. El bienestar futuro depende, como se ha dicho en el punto 3 , principalmente de la educación y cultura básica extensiva, a fin de que el individuo pueda ser el forjador de su destino.

El segundo punto es el referido a la tenencia de la tierra y la necesidad impostergable de llevar a cabo una verdadera reforma en esa área.

Las acciones de concentración parcelaria deben de establecerse en una política que cree incentivos para que muchos dueños de parcelas de hasta 5 hectáreas (el $85 \%$ de la tierra cultivada del país). se junten voluntariamente en asociaciones (sociedades anónimas o cooperativas) de no menos de 20 a 30 hectáreas. La base del éxito de Chile es que el promedio de los fundos está entre 30 y 40 hectáreas.

Estas unidades económicas de producción permiten la introducción de la tecnología moderna, pues sus rendimientos totales pueden asumir el costo de pagar esa tecnología. Conforme estas unidades se capitalicen, su influencia, tanto como la de los fundos más grandes, incentivarán y permitirán la afluencia de la técnica a los fundos más chicos.

En la medida en que el país vaya saliendo de la recesión se crearán puestos de trabajo en otras actividades que absorberán a muchos de los socios de las unidades asociativas, quienes venderán sus acciones o participaciones 


\section{EL FUTURO DE LOS ANDES}

al socio que más aptitud agrícola tenga, o se mantendrán como rentistas si el negocio es bueno.

Estas acciones deben de ser emprendidas por el Estado y deberán ir sustituyendo poco a poco a la permanente labor asistencialista actual.

7. Aparte de educación y reforma del agro, la otra actividad que puede influir grandemente en el desarrollo de esta zona es el incremento considerable del turismo. Esta actividad aparte de su gasto directo, crea gran cantidad de empleo indirecto en comercio, transporte, artesanía y todo tipo de servicios.

\section{Ricardo Soberón Garrido}

\section{Comisión Andina de Juristas}

1. La Sierra del Perú ocupaba en 1988 el $60 \%$ del área agrícola del país entre los 2000 y 4000 metros sobre el nivel del mar. $\mathrm{El} 30 \%$ de su población está mayoritariamente dedicada a la agricultura. Esta región se caracteriza por la diversidad de microclimas (hasta 52 zonas de vida). Sin embargo, de sus poco más de 39 millones de hectáreas, solamente el $3.42 \%$ puede servir para cultivos en limpio y $0.05 \%$ para cultivos permanentes, según información procedente de la anterior ONERN (1982).

La agenda futura de la sierra sur, en el próximo cuarto de siglo, pasa necesariamente por discutir y evaluar lo que el Estado y la iniciativa privada (nacional y extranjera) harán en cada una de las siguientes áreas:

- El futuro de los yacimientos de gas de Camisea $y$ el impacto de estas actividades sobre las poblaciones indígenas, sobre la economía regional y sobre la bio- 


\section{ENTRE PREVISIONES Y POSIBILIDADES}

diversidad amazónica; en particular deberán evaluarse los resultados económicos esperados de la concesión sin límites de estos yacimientos (a la Shell $o$ a quien gane el derecho), con los lineamientos establecidos en la Agenda XXI, en la misma Declaración de Río y los convenios específicos suscritos en la Cumbre de la Tierra (1992), todos ellos documentos provenientes de la misma Organización de las Naciones Unidas.

- El manejo binacional y compartido que se haga de los recursós existentes en la cuenca del Titicaca (agua, fauna $y$ flora), para el aprovechamiento en beneficio de las poblaciones aymaras y quechuas de Perú y Bolivia.

- La tendencia al crecimiento del proceso de "cocalización" subordinado al narcotráfico en el que se ven envueltas nuevas áreas en la vertiente oriental de los Andes: en Madre de Dios, en La Convención y el resto del valle del Urubamba, en el propio ámbito del departamento de Puno (Sandia). Así, áreas que anteriormente estuvieron dedicadas al cultivo tradicional de la hoja de coca, irán subordinándose a la demanda internacional. También debemos pensar que zonas menos templadas podrían dedicarse al cultivo ilegal de la amapola para derivarla a la producción del opio y su posterior conversión en heroína.

En el ámbito institucional, debemos partir de reconocer el agotamiento del anterior modelo de Estado asistencialista, el mismo que se encuentra en "vías de extinción». Pero ello, no debe significar una ausencia definitiva de autoridad institucional, ni de regulación última de las grandes decisiones nacionales, en beneficio del tejido social y no solamente de ciertos grupos económicos.

Creemos, en cuanto a esto último, que las reformas $y$ tendencias institucionales sucedidas en los últimos tres años van a llegar a su fin con el presente régimen (privatización indiscriminada, concentración del poder, ausencia de un Plan Nacional de Desarrollo ni de su correspondiente estrategia); la propuesta regional deberá 


\section{EL FUTURO DE LOS ANDES}

volver a sustentarse en la agenda política nacional, para ser discutida y ejecutada, ya no en los "congresos", sino en las mismas regiones $y$ microrregiones.

2. En realidad, la situación actual no nos proporciona elementos positivos que me permitan imaginar, siquiera, un futuro de «bienestar". Lamentablemente, los cambios profundos sucedidos en los últimos años en el escenario mundial, no han podido ser compartidos por los principales actores del campo; los campesinos y sus familias. América Latina está marginada de las tendencias mundiales, el Perú del proceso subregional y el Sur Andino del propio proceso peruano.

Las grandes tendencias de las variables nacionales se van a agudizar en materia de concentración de la población en zonas preferentemente urbanas, el escaso crecimiento del $\mathrm{PBI}$, individual $y$ sectorial, la creciente dependencia alimentaria de la población rural y los problemas estructurales relativos a la usustentabilidad" del desarrollo. Esto último debido a la situación de la erosión de los suelos, la pérdida de calidad de los cursos de agua, la falta de manejo en los centros de crecimiento poblacional, entre otros.

\section{Reynaldo Trinidad Ardiles}

\section{AGRONOTICIAS, Revista para el desarrollo}

1. Sin duda, el futuro previsible para la sierra sur del Perú es el mismo que para el resto del país, aunque con algunos matices singulares y acordes con ciertas características propias de la región. Me explico: salvo un viraje 


\section{ENTRE PREVISIONES Y POSIBILIDADES}

radical en el antinacional, antipopular, antiprovinciano $y$ anticampesino "modelo de desarrollo" que viene siguiendo el país, no se puede esperar ningún cambio estructural favorable para las grandes mayorías nacionales $y$ regionales en los próximos años. Pues el contexto político-económico global es el gran condicionante del avance, el estancamiento o el retroceso de los pueblos, aun cuando ciertos segmentos escapen a la regla, precisamente para confirmarla.

Sin embargo, también es probable que los sectores populares y campesinos despierten más rápido que otrora a la elemental comprobación de que el futuro del Perú no pasa por ningún extremismo -estatista, populista o neoliberalsino por la organización racional y democrática de las masas para cambiar el curso de la historia por medio del voto universal $y$ secreto, dado que la mayor fuerza de nuestro pueblo -un verdadero poder en latencia- está en su milenaria capacidad de trabajo solidario y su enorme -pero casi nunca bien orientado- caudal eleccionario.

2. Una de las grandes cosas que tenemos que aprender los peruanos en general es a no mirar a nuestro país como a un todo uniforme, como to hacen los neoliberales fundamentalistas. El nuestro es un país natural y culturalmente muy diverso, donde las recetas únicas, rígidas $y$ excluyentes no valen, ni siquiera en ámbitos que exteriormente parecen muy homogéneos, como en el caso del Sur Andino, donde por ejemplo hay que saber entender, primero, la idiosincrasia de los quechuas, los chankas y los aymaras, para luego proponer $y$ ejecutar cualquier alternativa de desarrollo.

Hecha esta salvedad, creo que el momento ofrece una pequeña gran posibilidad para vislumbrar $e$ intentar construir un futuro relativamente mejor para los segmentos campesinos y urbano-marginales más necesitados del Sur Andino y del Perú entero: la organización empresarial, bajo la modalidad que sea, aunque con la mayor dosis posible 


\section{EL FUTURO DE LOS ANDES}

de solidaridad y equidad interna, para darles a los pobres una elemental capacidad de interlocución y negociación con terceros, a partir de un cierto poder económico.

En tal sentido, debemos adoptar ese sabio $y$ pragmático principio chino que reza: "No importa qué color tenga el gato. Lo importante es que cace ratones". Principio que encaja perfectamente con la gran diversidad de nuestro país; hecho sobre el cual debemos agregar otro concepto básico: la única forma de derrotar a la pobreza es generando riqueza. $\mathrm{Y}$ para generar riqueza, no hay mejor instrumento que hacer empresa, deselitizando $o$ desoligarquizando la actual connotación de ésta, puesto que -históricamente- la empresa no fue ni es creación del capital o dinero, sino de inventiva y el trabajo del hombre.

Dentro de este marco, las empresas campesinas $y$ populares resultan decisivas, por ejemplo, para cerrar el circuito económico de los cultivos y crianzas andinos, empezando por concertar un gran poder de negociación para abastecer directamente a los mercados sujetos a voluntad del Estado o «mercados cautivos", desde los programas de desayunos escolares y comedores populares, pasando por las cárceles y hospitales, hasta los institutos armados y policiales.

Para el efecto, basta perfeccionar las experiencias que ya se están dando hoy mismo con el PRONAA, pero que no avanzan como debieran, precisamente por la carencia de una adecuada capacidad empresarial en el frente de la oferta: los campesinos.

Además, ¿por qué han de ser empresarios (y ricos) sólo los mercaderes, y no los buenos cristianos? 


\section{Juan José Vera del Carpio Asociación de Promoción Agraria}

1. Cualquier previsión que se haga sobre las posibilidades de desarrollo de la región surandina debe partir del hecho que nos encontramos en la más crítica situación que hayamos podido imaginar quienes desde los años 60 , de alguna $u$ otra manera, estamos ligados a la vida $y$ aspiraciones de la región.

Las posibilidades futuras podríamos sistematizarlas en dos etapas. La primera, la del reordenamiento $y$ recuperación $y$, la segunda, del desarrollo y crecimiento sostenido.

Considero que debe rescatarse del texto de la pregunta el horizonte temporal de 25 años, pues no me cabe la menor duda que lograr resultados objetivos en la sierra sur es un trabajo de largo aliento $y$ en muchos aspectos generacional, en donde, lamentablemente, las décadas y no los años son los periodos de referencia.

En cuanto a la viabilidad de la etapa del reordenamiento y la recuperación, la consideramos posible y urgente. Se necesita, primero, reordenar ideas, corregir los vicios de la «ideologización» del proceso de desarrollo $y$, luego, un examen sincero y profundo de los errores cometidos $y$ un replanteo de las estrategias realizadas.

En este primer punto se requiere que algunos actores principales, en especial las dirigencias gremiales campesinas, estratos políticos locales, una parte de la propia jerarquía de la Iglesia Católica $y$, en general, todos los vinculados al tema, hagamos un acto de contricción y un propósito de enmienda, para que sepamos ser más prudentes en nuestras prédicas sociales que consideramos correctas $o$, en otros casos, como el mío, por no haber puesto más empeño en combatir algunos errores, tal como 


\section{EL FUTURO DE LOS ANDES}

fue la lamentable decisión de reestructuración de las empresas asociativas en el altiplano.

La recuperación implica emprender un nuevo proyecto para el Sur Andino en un contexto social, organizativo y productivo muy diferente a las prácticas y prédicas de las últimas décadas.

La segunda etapa, de desarrollo y crecimiento, debe estar vinculada a una estrategia que permita mejores condiciones de vida, a partir de un renovado aparato productivo, que pueda atender los dos problemas centrales del Sur Andino: la falta de empleo y la escasez de alimentos.

2. Creo firmemente que el desarrollo debería basarse en la potenciación de la calidad y preparación de las poblaciones andinas; en la explotación sustentable de sus recursos naturales; en aprovechar las innegables ventajas comparativas que se tiene $y$ en una adecuada inserción a una economía de mercado, que nos libere de las prácticas paternalistas que sólo han servido para agudizar la miseria, y que en los últimos 15 años han llevado a nuestros campesinos a pasar de las duras economías de subsistencia a dramáticos niveles de mendicidad.

El desarrollo en el Sur Andino debe combinar las mejores tradiciones culturales de nuestro campesinado con los desafíos que presenta la modernidad del siglo XXI. Esto deberá sustentarse en una nueva organización económico productiva, que inicialmente requerirá del ahorro extra regional, a ser aplicado sólo en unidades donde la rentabilidad financiera y económica combine las propuestas de empleo, producción de alimentos y viabilidad socio cultural. 


\section{ENTRE PREVISIONES Y POSIBILIDADES}

\section{Ricardo Vergara Belaúnde}

Seguimiento, Análisis y Evaluación para el Desarrollo, SASE

1. Luego de la inmensa debacle que representó para el Sur Andino ${ }^{1}$ la independencia republicana, es probable que en los próximos 25 años continúe acelerándose el proceso de urbanización y modernización actualmente en curso. En 1972 habían solamente tres ciudades con más de $20 \mathrm{mil}$ habitantes (Cusco, Juliaca y Puno) y en 1993 llegaron a ser siete (las 3 anteriores más Abancay, Andahuaylas, Sicuani y Quillabamba). Es previsible que, dentro de 25 años, este tipo de ciudades lleguen a ser alrededor de trece.

En el 2019 la población total habrá llegado a los 3.5 millones de habitantes, representando un aumento de más o menos $45 \%$. Los residentes en ciudades con más de 20 mil habitantes, que triplicaron su población en los últimos 21 años, probablemente duplicarán su volumen en los próximos 25 años, pasando de los 600 mil actuales a 1'200 mil habitantes.

El mercado de alimentos regional -que se incrementará como consecuencia de este aumento poblacional urbano y la mejora de sus ingresos promedioimpulsará una moderada modernización agropecuaria en los ámbitos ganaderos (de auquénidos y vacuno) y agrícola en el piso de valle. El aumento del costo de oportunidad de la mano de obra campesina apurará la emigración de los minifundistas en secano acentuándose el envejecimiento de la población.

La mejora de la comunicación vial en los ejes Sicuani-Arequipa y Juliaca-Arequipa permitirá que la agri-

1 El ámbito geográfico al que se refieren estas líneas corresponde a los departamentos de Apurímac, Cusco y Puno. 


\section{EL FUTURO DE LOS ANDES}

cultura arequipeña modere las posibilidades andinas de beneficiarse con el aumento de la demanda urbana, pero, a cambio de esto, permitirá que la emigración rural se acentúe, generando oportunidades para emigrar. En la misma dirección influirán los ejes viales: Puno-llo-Moquegua y Desaguadero-Tacna.

La integración con Brasil y Bolivia generará ventajas de lugar central para las ciudades puneñas. La selva de Madre de Dios seguirá creciendo aceleradamente pero sin llevar a representar un peso demográfico decisivo.

Arequipa reforzará su papel de capital regional apoyándose en su capacidad de liderar intelectual $y$ empresarialmente el proceso de modernización. El Gran Sur, aislado por el angostamiento que debilita la franja costera pasando lca y vinculado más fuertemente con Chile, Brasil y Bolivia, se encamina hacia una época de mayor prosperidad y para esto no será necesario que el capital financiero internacional decida invertir en grandes proyectos de extracción o transformación.

2. La posibilidad de un futuro de bienestar para las poblaciones del Sur Andino se sustenta en cuatro rasgos principales: a. en el dinamismo urbano actualmente existente, que no se debe a ningún evento coyuntural sino a la articulación entre ciudades $y$ entre ciudad $y$ campo andino; b. en la proyección realista de los planes de integración internacional; c. en las posibilidades de densificar la trama vial de penetración, y $\mathrm{d}$. en la perspectiva de un relanzamiento de la economía mundial.

Existen, sin embargo, grandes riesgos. El primero nace de que la diversidad étnica (hispano hablantes, quechuas y aymaras) pueda convertirse en un impasse político. En la actualidad parece improbable pero la experiencia mundial prueba que el asunto de las nacionalidades puede convertirse fácil y rápidamente en una cuestión explosiva. Si la élite regional que se está formando tiende a definirse a partir de una conciencia de minoría étnica 


\section{ENTRE PREVISIONES Y POSIBILIDADES}

contestaría, entonces, la región corre un grave riesgo. Paradójicamente esta tendencia late con mayor fuerza entre los mestizos, descendientes de los españoles empobrecidos a lo largo de la república, que forman parte de las élites intelectuales y políticas de la región.

Un segundo riesgo es el que no llegue a consolidarse suficientemente una ideología modernizante que sustente una propuesta para la acción y no para el reclamo. Hay aqui una gran responsabilidad para los agentes pastorales comprometidos con la promoción del desarrollo local. Luego de años de vivir vinculados $y$ solidarizados con los más pobres, en medio de un mundo caracterizado por la mayor precariedad, es difícil no tener una visión donde predominan los problemas en lugar de las posibilidades. Como se dio en decir, tender a la protesta en lugar de la propuesta.

El asunto es de real envergadura $y$ tiene que ver con el fondo de las cosas, como la formación de sujetos históricos -económicos y políticos- que se sientan capaces de asumir la responsabilidad de transformar el mundo que los rodea. Me parece claro que si no se apoya la formación de empresarios y ciudadanos las oportunidades se van a ver fuertemente frenadas, habrá un divorcio entre los líderes económicos que compiten por desarrollar oportunidades y los políticos que deslegitiman el éxito. $\mathrm{Si}$ se emparentan el resentimiento étnico y la ética social del medioevo las cosas se pueden complicar enormemente; felizmente, tanto entre los aymaras como entre los quechuas que construyen exitosamente Juliaca, Sicuani o llave, la modernización no parece encontrar las resistencias que desgraciadamente subsisten entre algunos intelectuales. 